\title{
Specificity of time- and dose-dependent morphological endpoints in the fish embryo acute toxicity (FET) test for substances with diverse modes of action: the search for a "fingerprint"
}

\author{
Rebecca von Hellfeld ${ }^{1,2} \cdot$ Pauline Pannetier $^{1} \cdot$ Thomas Braunbeck $^{1}$ (D) \\ Received: 24 February 2021 / Accepted: 1 September 2021 / Published online: 13 October 2021 \\ (C) The Author(s) 2021
}

\begin{abstract}
The fish embryo acute toxicity (FET) test with the zebrafish (Danio rerio) embryo according to OECD TG 236 was originally developed as an alternative test method for acute fish toxicity testing according to, e.g., OECD TG 203. Given the versatility of the protocol, however, the FET test has found application beyond acute toxicity testing as a common tool in environmental hazard and risk assessment. Whereas the standard OECD guideline is restricted to four core endpoints (coagulation as well as lack of somite formation, heartbeat, and tail detachment) for simple, rapid assessment of acute toxicity, further endpoints can easily be integrated into the FET test protocol. This has led to the hypothesis that an extended FET test might allow for the identification of different classes of toxicants via a "fingerprint" of morphological observations. To test this hypothesis, the present study investigated a set of 18 compounds with highly diverse modes of action with respect to acute and sublethal endpoints. Especially at higher concentrations, most observations proved toxicant-unspecific. With decreasing concentrations, however, observations declined in number, but gained in specificity. Specific observations may at best be made at test concentrations $\leq$ $\mathrm{EC}_{10}$. The existence of a "fingerprint" based on morphological observations in the FET is, therefore, highly unlikely in the range of acute toxicity, but cannot be excluded for experiments at sublethal concentrations.
\end{abstract}

Keywords Fish embryo toxicity test $\cdot$ Zebrafish $\cdot$ Danio rerio $\cdot$ OECD TG $236 \cdot$ Acute toxicity $\cdot$ Sublethal toxicity $\cdot$ Specificity $\cdot$ Sensitivity

\section{Introduction}

In 2019, the European Union produced 277.8 million tons of hazardous chemicals (Eurostat 2020), and, according to CEFIC (2021) and Statista (https://www.statista.com/), the 2018 global

Responsible Editor: Philippe Garrigues

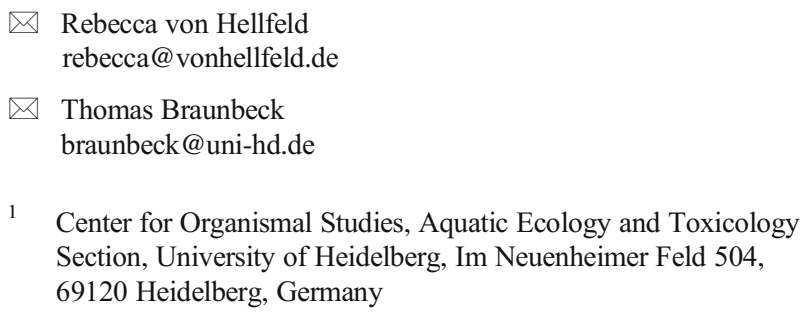

2 Present address: University of Aberdeen, Institute of Biological and Environmental Science, 23 St Machar Drive, AB24 3UU, Aberdeen, UK 
plant protection products, pharmaceuticals, biocides, feed additives, and effluents (Scholz et al. 2013), this increase in testing requirements has raised increasing concern about animal welfare (Braunbeck et al. 2005, 2015; Paparella et al. 2020; von Hellfeld et al. 2020). In order to meet these concerns, in 2003, Germany replaced whole effluent acute fish toxicity (AFT) testing according to OECD TG 203 (OECD 1992, 2019) with the zebrafish (Danio rerio) fish egg test (Bundesgesetzblatt 2005; ISO 2007), and, in 2013, the OECD adopted the fish embryo acute toxicity (FET) test (TG 236; (OECD 2013)) as an alternative method for the AFT test. According to current EU Animal Welfare Regulation (EU 2010), zebrafish embryos are not regarded protected according to current EU animal welfare legislation (Strähle et al. 2012).

In order to provide equivalent sensitivity to the AFT test (OECD 1992, 2019), the original FET test protocol (OECD 2013) was designed to use only 4 morphological core endpoints: coagulation of the embryo, lack of somite formation, lack of heartbeat, and non-detachment of the tail (OECD 2013). These endpoints were selected for (1) their direct or indirect association with mortality, (2) their practicality for screening by well-trained technical staff, and (3) their ease for recording and reporting. Over the last two decades, however, the zebrafish embryo has also been developed further into one of the most promising models not only in ecotoxicity testing (Braunbeck et al. 2015), but also in mammalian toxicology (Nagel 2002; Ton et al. 2006; Braunbeck 2009; Brannen et al. 2010; Sipes et al. 2011; Sukardi et al. 2011; Ali et al. 2011; De Esch et al. 2012; Driessen et al. 2013; Scholz et al. 2013; Nishimura et al. 2015; Guo et al. 2015; Bambino and Chu 2017; Fernandes et al. 2018). The versatility of the FET test has thus prompted a massive expansion of the scope of the FET test, which, in turn, led to the integration of numerous further endpoints into the original FET protocol and resulted in a rapidly growing list of not only morphological observations, but also physiological, biochemical, and molecular endpoints.

In fact, exposure of aquatic biota to environmental pollutants can lead to a multitude of specific or unspecific adverse effects, which may easily become relevant for the performance of populations via, e.g., feminization due to exposure to estrogenic compounds (Matthiessen et al. 2018; Wolf and Wheeler 2018; Dang and Kienzler 2019), or via behavioral changes due to neurotoxicity by heavy metals, organochlorine compounds, or pesticides (De Esch et al. 2012; Dhillon et al. 2015; Yueh and Tukey 2016; Nishimura et al. 2016; Green and Planchart 2018)). Whereas estrogen-receptor-mediated feminization is - by definition-a specific process, behavioral changes are likely to be unspecific (Tilton et al. 2011), unless target-specific molecular interactions like inhibition of enzymes such as acetyl choline esterase inhibition by phosphate ester pesticides and carbamates are concerned (Fulton and Key 2001; Behra 2004; Yen et al. 2011; Russom et al. 2014; Kais et al. 2015). The distinction between specific and unspecific endpoints may deepen the current understanding of adverse effects on populations and in risk assessment.

While most apical endpoints of acute toxicity are per se nonspecific, tests addressing more specific endpoints such as endocrine disruption, genotoxicity, neurotoxicity, or immunotoxicity hold greater potential to yield specific reactions (Nendza and Wenzel 2006; Singh et al. 2019; Li et al. 2019). Especially with the advent of molecular techniques in (eco-)toxicology, the hypothesis developed that specific changes of a combination thereof might serve as a "fingerprint" of the contaminant or contaminant class (Peterson and Bain 2004; Yang et al. 2009; Gagné et al. 2013; Zhang et al. 2015; Neale et al. 2017). The massive diversification of FET test protocols has thus also led to the hypothesis that an extended FET test might allow for the identification of different classes of toxicants via a "fingerprint" of morphologically detectable observations. To test this hypothesis, the present study investigated 18 compounds with highly diverse modes of action with respect to acute and sublethal morphological endpoints in the FET test. In order to characterize the specificity of the morphological observations, data were analyzed not only with respect to their assignment to specific substances or substance classes, but also with regard to their time- and dose-dependence.

\section{Materials and methods}

\section{Chemicals and test substances}

Test compounds were selected for the diversity of their modes of action. Primary mode(s) of action as well as detailed information on the preparation of test solutions are summarized in Table 1. All compounds tested were purchased at a minimum purity of $98 \%$. Paraquat, carbaryl, colchicine, rifampicin, clofibrate, sulfisoxazole, and taxol were obtained from Carbosynth (Compton, UK); rotenone, tebuconazole, and ibuprofen were obtained from TCI (Eschborn, Germany); and acrylamide, hexachlorophene, 1-methyl-4-phenyl-pyridinium iodide $\left(\mathrm{MPP}^{+}\right)$, paracetamol, PCB 180 , tolbutamide, triphenylphosphate, and valproic acid were purchased from Sigma-Aldrich (Deisenhofen, Germany). Dimethyl sulfoxide (DMSO) was ordered from Honeywell International (Offenbach, Germany). All test solutions were freshly prepared immediately prior to use in standardized water (ISO 1996); in cases of limited water solubility, DMSO was used as a solvent: clofibrate, hexachlorophene, rotenone, tebuconazole, tolbutamide, and valproic acid were dissolved in $0.1 \%$ DMSO, whereas carbaryl and ibuprofen were dissolved in $0.5 \%$ DMSO, which has been determined as an acceptable concentration for FET test experiments in previous studies (Maes et al. 2012; Christou et al. 2020). PCB 180, rifampicin, sulfisoxazole, and taxol were dissolved in $1 \%$ DMSO, since no adverse effects were observed at the highest test concentrations, when dissolved in $0.5 \%$ DMSO. When 
Table 1 Test compounds used in the acute fish embryo toxicity tests with the zebrafish (Danio rerio) embryo: media and exposure concentrations as well as primary mode(s) of action according to literature data

\begin{tabular}{|c|c|c|c|c|}
\hline Compound & Solution medium & Test concentrations $(\mathrm{mg} / \mathrm{L})$ & Mode(s) of action & References \\
\hline Acrylamide & $\mathrm{H}_{2} \mathrm{O}$ & $43.75,87.5,175,350$ & $\mathrm{ED}, \mathrm{MCI}$ & Tyl and Friedman (2003), Faria et al. (2018) \\
\hline Carbaryl & $0.5 \%$ DMSO & $1.89,3.75,7.5,15$ & AI, CYP & Slaninova et al. (2009), Schock et al. (2012) \\
\hline Clofibrate & $0.1 \%$ DMSO & $62.5,125,250,500,1000$ & PM, OX & Laville et al. (2004), Den Broeder et al. (2015) \\
\hline Colchicine & $\mathrm{H}_{2} \mathrm{O}$ & $10,20,40,80$ & MT & Jesús et al. (1987) \\
\hline Hexachlorophene & $0.1 \%$ DMSO & $2,4,8,16,32$ & MCI & Zheng et al. (2012) \\
\hline Ibuprofen & $0.5 \%$ DMSO & $2.50,5,10,20,40,80$ & PM, CI & David and Pancharatna (2009a), Puhl et al. (2015) \\
\hline $\mathrm{MPP}^{+}$ & $0.1 \%$ DMSO & $100,200,400,800,1600$ & HDAC & Pinho et al. (2016) \\
\hline Paracetamol & $\mathrm{H}_{2} \mathrm{O}$ & $125,250,500,1000,2000$ & $\mathrm{OX}, \mathrm{CI}$ & David and Pancharatna (2009b), Du et al. (2016) \\
\hline Paraquat & $\mathrm{H}_{2} \mathrm{O}$ & $125,250,500,1000$ & OX & Slaninova et al. (2009), Lushchak (2016) \\
\hline PCB 180 & $1.0 \%$ DMSO & $3.13,6.25,12.50,25$ & cGMP & Llansola et al. (2009) \\
\hline Rifampicin & $1.0 \%$ DMSO & $50,100,200,400,800$ & CYP & Mahatthanatrakul et al. (2007) \\
\hline Rotenone & $0.1 \%$ DMSO & $2,4,8,16,32$ & MCI, OX & $\begin{array}{l}\text { Cheng and Farrell (2007), Slaninova et al. (2009), } \\
\text { Pinho et al. (2013), Wang et al. (2017) }\end{array}$ \\
\hline Sulfisoxazole & $1.0 \%$ DMSO & $50,175,250,500,1000$ & $\mathrm{BAC}, \mathrm{CYP}$ & Hong et al. (1995) \\
\hline Taxol & $1.0 \%$ DMSO & $6.25,12.50,25,50$ & OX, MT & Brito et al. (2008), Lisse et al. (2016) \\
\hline Tebuconazole & $0.1 \%$ DMSO & $1.88,3.75,7.50,15,30$ & $\mathrm{ED}, \mathrm{CYP}, \mathrm{OX}$ & Sancho et al. (2010), Yang et al. (2018) \\
\hline Tolbutamide* & $0.1 \%$ DMSO & $57.34,71.60,89.60,112,140$ & MCI & Zhou et al. (2009) \\
\hline Triphenylphosphate & $0.1 \%$ DMSO & $0.19,0.38,0.75,1.50,3$ & ED, CYP, PM & Isales et al. (2015), Du et al. (2016), Liu et al. (2016) \\
\hline Valproic acid & $0.1 \%$ DMSO & $3,7,14,29,58,115$ & HDAC, MCI & Chateauvieux et al. (2010), Godhe-Puranik et al. (2013) \\
\hline
\end{tabular}

Abbreviations: $A I$ acetylcholine esterase inhibition, $B A C$ bacterial inhibition, $c G M P$ glutamate-NO-cGMP pathway inhibition, $C I C O X$ inhibition, $C Y P$ CYP450 inhibition, $E D$ endocrine disruption, $H D A C$ HDAC inhibition, $M C I$ membrane channel inhibition, $M T$ microtubule binding, $O X$ oxidative stress, PM PPAR modulation

*pH of the final solutions had to be adjusted

the DMSO concentration was even further increased to $1 \%$ and no effect was seen at the highest test concentration, these compounds were not tested further to avoid interference of DMSO toxicity with the observations (Table 1). Additional information on $\log K_{\mathrm{OW}}$, solubility, and stability as well as application profiles and biological effects is provided in Supplemental materials Tables 1 and 2.

\section{Fish maintenance}

Adult wild-type zebrafish of the Westaquarium strain were obtained from breeding facilities at the Aquatic Ecology and Toxicology Group within the Centre for Organismal Studies (University of Heidelberg; licensed under no. 35-9185.64/ $\mathrm{BH})$. Fish maintenance, breeding conditions, and egg production were described in detail by Lammer et al. (2009) and are in accordance with internationally accepted standards.

\section{Fish embryo acute toxicity test (OECD TG 236)}

The acute toxicity of the test substances was determined according to OECD TG 236 (OECD 2013). In brief, freshly spawned eggs ( $<1 \mathrm{~h}$ post-fertilization (hpf)) were transferred to $50-\mathrm{ml}$ crystallizing dishes filled with the respective test solutions. After control of the fertilization success, eggs were individually transferred to 24-well plates (TPP, Trasadingen, Switzerland) filled with $2 \mathrm{ml}$ of test solution per well (1 embryo per well). All test vessels had been pre-incubated (saturated) with the test solutions for at least $24 \mathrm{~h}$. Subsequently, well plates were sealed with self-adhesive foil (SealPlate ${ }^{\circledR}$ by EXCEL Scientific, Dunn, Asbach, Germany) and were placed in a Binder KT incubator (Tuttlingen, Germany) at $26.0 \pm 1.0^{\circ} \mathrm{C}$ under a 10/14-h dark/light regime. The test medium was renewed each day (semi-static exposure), and all developmental alterations of the embryos were documented at 24, 48, 72, and $96 \mathrm{hpf}$, according to OECD TG 236 (OECD 2013) and Nagel (2002), respectively. FET tests with a minimum mortality rate of $30 \%$ in the positive control (4 mg/L 3.4-dichloroaniline (DCA)) and a maximum effect rate of $10 \%$ in the negative control (dilution water) at $96 \mathrm{hpf}$ were classified as valid.

In addition to the endpoints specified by OECD TG 236, namely (1) coagulation of fertilized eggs, (2) lack of somite formation, (3) non-detachment of tail bud, and (4) lack of heartbeat (OECD 2013), any other observation was recorded as further lethal or sublethal morphological endpoints: 
Common examples were reduced heartbeat or reduced blood flow, inhibited or missing pigmentation, delayed or altered development, modified movement(s), distortion of the spine, craniofacial deformations, eye development, delayed hatching and fin formation, and formation of various types of edema (von Hellfeld et al. 2020). In the case of evidence for delayed toxicity, the standard exposure duration of $96 \mathrm{~h}$ specified by OECD TG 236 (OECD 2013) was extended to $120 \mathrm{~h}$. In any case, the developmental stage at the end of the experiments never exceeded the limits for unprotected developmental stages set by the current EU animal welfare legislation (EU 2010; Strähle et al. 2012). In case 2 range-finding experiments already provided conclusive results, only two replicates of the definitive FET test with 5 test concentrations spaced by a factor not larger than 2 were conducted for each compound. Otherwise, 4 replicates of the full FET test were conducted. The embryos were analyzed individually under an Olympus CKX41 inverted microscope (Olympus, Hamburg, Germany), and images were captured using an Olympus C5040 AUD camera.

\section{Data analysis and statistics}

Lethal concentrations (LC) for the 4 core endpoints listed in OECD TG 236 (OECD 2013) as well sublethal effect concentrations (EC) based on the 4 core endpoints plus any other effect were calculated at levels of 10 and $50 \%$ based on probit analysis using linear maximum likelihood regression with ToxRat ${ }^{\circledR}$ (ver. 2.10.06; ToxRat ${ }^{\mathrm{TM}}$ Solutions, Alsdorf, Germany), with both lethal and sublethal effects included into the calculation of EC values (Hrovat et al. 2009). The relative frequencies of morphological observations were calculated as follows: The percentage of coagulated embryos was calculated based on the total number of individuals of the given concentration, whereas the percentage of the other 3 lethal endpoints (lack of somite formation, tail detachment, and heartbeat) was computed based on the number of non-coagulated individuals. Relative percentages for sublethal effects were calculated on the basis of surviving embryos. Data were also analyzed for time-dependent changes in LC values for 72-hold embryos via ANOVA-on-ranks (Kruskal-Wallis) followed by Dunn's post hoc test, as included in SigmaPlot Version 13.0.0.83 (Systat-Jandel, Erkrath, Germany).

\section{Results and discussion}

\section{Formal lethal and sublethal toxicity data from the standard fish embryo acute toxicity test (OECD TG 236)}

Out of the 18 compounds tested, 13 expressed morphologically observable effects in the FET test (Table 2). Although tested with a maximum final DMSO concentration of $1 \%$, PCB 180 , rifampicin, sulfisoxazole, and taxol did not produce any effect up to the highest concentrations tested (cf. Table 1). Likewise, $\mathrm{MPP}^{+}$was tested to a final concentration of $1.6 \mathrm{~g} / \mathrm{L}$, but failed to induce any morphological sign of toxicity and was, therefore, excluded from further analysis.

The two most toxic compounds were rotenone and hexachlorophene, both with $\mathrm{EC}_{10}$ values of $4 \mu \mathrm{g} / \mathrm{L}$ ( \pm 0.3 and \pm 0.1 $\mu \mathrm{g} / \mathrm{L}$, respectively). Apart from paraquat, the remaining pesticides also produced sublethal effects at very low concentrations, whereas the pharmaceuticals caused toxic effects at highly variable concentration levels. The $\mathrm{EC}_{10}$ of valproic acid, e.g., was found to be $5.0 \pm 0.7 \mathrm{mg} / \mathrm{L}$, while $\mathrm{EC}_{10}$ values for paracetamol and clofibrate were $>200 \mathrm{mg} / \mathrm{L}( \pm 2.9$ and \pm $36.7 \mathrm{mg} / \mathrm{L}$, respectively); trends for lethal toxicity (LC) values were similar. As a rule, toxicity data for pharmaceuticals also spanned a larger range (flat slope of the concentrationresponse relationship): For instance, ibuprofen had an $\mathrm{EC}_{10}$ value of $4.7 \pm 1.47 \mathrm{mg} / \mathrm{L}$ and an $\mathrm{LC}_{50}$ value of $37.3 \pm 3.48 \mathrm{mg} /$ $\mathrm{L}$, and valproic acid ranged from $5.0 \pm 0.73 \mathrm{mg} / \mathrm{L}\left(\mathrm{EC}_{10}\right)$ to $37.4 \pm 2.91 \mathrm{mg} / \mathrm{L}\left(\mathrm{LC}_{50}\right)$. In contrast, the concentrationresponse relationship of the insecticide carbaryl displayed a much steeper slope, i.e., sublethal and lethal toxicity data were much closer $\left(\mathrm{EC}_{10}, 2.2 \pm 0.26 \mathrm{mg} / \mathrm{L}\right.$, and $\mathrm{LC}_{50}, 12.2 \pm 0.72$ $\mathrm{mg} / \mathrm{L}$ ). For further details and analyses of LC and EC data in zebrafish embryos, see von Hellfeld et al. (2020), where FET observations were discussed in the context of a catalog of FET endpoints.

\section{Further FET test observations and their potential for substance specificity}

Morphological observations recorded throughout the $96 \mathrm{~h}$ of exposure were categorized into (1) a group of clearly "sublethal effects" (occurring at concentrations $<\mathrm{EC}_{50}$, Table 3 ) and (2) a group of endpoints recorded at a concentration between $\mathrm{EC}_{50}$ and $\mathrm{LC}_{50}$ values ("lethal effects," Table 4). Given that the 4 core endpoints listed by OECD TG 236 had been selected as a clear indicator of mortality, these could only rarely be recorded at exposure concentrations $<\mathrm{EC}_{50}$; in fact, only coagulation and missing heartbeat could be identified at concentrations ( $<10 \%$ of individuals) below which no other endpoint was positive (Table 3); in such cases, acute lethality drives the lowest observed effect concentration (LOEC).

In the present study, by definition, observations recorded after exposure to more than 4 of the separately tested substances (> 30\% of the toxic substances) were classified as "unspecific," if this observation was true at lethal concentrations. Here, all non-OECD endpoints observed at concentrations $<\mathrm{EC}_{50}$ were either induced by exposure to at least 4 of the tested compounds or represented different aspects of the same impaired system (e.g., missing heartbeat and reduced heartbeat). They were thus all classified as unspecific and 
Table 2 Subletal and acute toxicity of selected test compounds (EC and LC values at 10 and $50 \%$ effect levels) in embryos of the zebrafish (Danio rerio) at $96 \mathrm{hpf}$

\begin{tabular}{lllll}
\hline & $\mathbf{E C}_{\mathbf{1 0}}$ & $\mathbf{E C}_{\mathbf{5 0}}$ & $\mathbf{L C}_{\mathbf{1 0}}$ & $\mathbf{L C}_{\mathbf{5 0}}$ \\
\hline Acrylamide $(\mathrm{mg} / \mathrm{L})$ & $75.5 \pm 13.09$ & $94.3 \pm 7.8$ & $154.6 \pm 53.2$ & $205.7 \pm 3.1$ \\
Carbaryl $(\mathrm{mg} / \mathrm{L})$ & $2.2 \pm 0.3$ & $2.4 \pm 0.2$ & $6.6 \pm 1.6$ & $12.2 \pm 0.7$ \\
Clofibrate $(\mathrm{mg} / \mathrm{L})$ & $213.3 \pm 36.7$ & $342.5 \pm 53.9$ & $602.7 \pm 36.1$ & $1113.2 \pm 23.6$ \\
Colchicine $(\mathrm{mg} / \mathrm{L})$ & $23.1 \pm 3.9$ & $32.4 \pm 2.9$ & $32.5 \pm 8.4$ & $41.4 \pm 6.5$ \\
Hexachlorophene $(\mu \mathrm{g} / \mathrm{L})$ & $4.0 \pm 0.1$ & $5.0 \pm 0.1$ & $7.0 \pm 0.3$ & $8.0 \pm 0.3$ \\
Ibuprofen $(\mathrm{mg} / \mathrm{L})$ & $4.7 \pm 1.5$ & $10.8 \pm 2.9$ & $31.7 \pm 2.1$ & $37.3 \pm 3.5$ \\
Paracetamol $(\mathrm{mg} / \mathrm{L})$ & $219.8 \pm 2.9$ & $262.6 \pm 2.4$ & $1000 \pm 0.1$ & $1167.5 \pm 3.1$ \\
Paraquat $(\mathrm{mg} / \mathrm{L}) *$ & $384.7 \pm 64.3$ & $545.9 \pm 7.2$ & $721.1 \pm 8.1$ & $855.0 \pm 4.8$ \\
Rotenone $(\mu \mathrm{gg} / \mathrm{L})$ & $4.0 \pm 0.1$ & $7.1 \pm 1.0$ & $6.0 \pm 1.2$ & $10.0 \pm 2.3$ \\
Tebuconazole (mg/L) & $2.3 \pm 0.1$ & $5.3 \pm 0.2$ & $15.0 \pm 0.1$ & $17.3 \pm 0.1$ \\
Tolbutamide $(\mathrm{mg} / \mathrm{L})$ & $54.3 \pm 12.3$ & $116.9 \pm 14.1$ & $223.2 \pm 6.9$ & $278.6 \pm 8.4$ \\
Triphenylphosphate $(\mathrm{mg} / \mathrm{L})$ & $0.3 \pm 0.1$ & $0.5 \pm 0.1$ & $1.4 \pm 0.1$ & $1.6 \pm 0.1$ \\
Valproic acid $(\mathrm{mg} / \mathrm{L}) *$ & $5.0 \pm 0.8$ & $7.8 \pm 1.0$ & $33.7 \pm 7.8$ & $37.4 \pm 2.9$ \\
\hline
\end{tabular}

*Exposure duration extended to $120 \mathrm{hpf}$ occurred at low frequencies. As could be expected, the number of effects increased with the transition from effects $<\mathrm{EC}_{50}$ (Table 3) to effects between $\mathrm{EC}_{50}$ and $\mathrm{LC}_{50}$ (Table 4), i.e., with increasing concentration (positive concentrationresponse relationship). In parallel, the number of individuals affected (frequencies of occurrence) increased.

The most frequent observations recorded at sublethal concentrations (Table 3 ) were craniofacial deformation and lack of hatching ( 8 compounds), followed by coagulation ( 7 compounds) and formation of pericardial edemata ( 6 compounds). The endpoints observed with the lowest number of test compounds were impaired pigmentation and impaired fin development (1 compound each). Further endpoints observed less frequently were effects in the circulatory system such as impaired heartbeat and blood flow ( 2 compounds), as well as lack of heartbeat, reduced yolk resorption, and tremor (3 compounds). Overall, more adverse endpoints such as lack of blood flow, blood congestion, lordosis, and the OECD TG 236 core endpoints were less frequently observed.

As a rule, both numbers and frequencies of positively recorded endpoints decline with test concentrations. A remarkable exception is paracetamol (Table 3): At only $\leq \mathrm{EC}_{50}$ concentrations, coagulation (in 3 and $10 \%$ of the exposure groups) and reduced yolk resorption (3\%) could be observed. A high number of individuals also displayed impaired pigmentation (up to $100 \%$, which declined to $94 \%$ at concentrations between $\mathrm{EC}_{50}$ and $\mathrm{LC}_{10}$ ). For most other endpoints, the frequencies of observations were limited to $\leq 20 \%$, (exception: $27 \%$ lordosis with acrylamide). Overall, given the increasing lack of systemic responses at concentration levels well below $\mathrm{EC}_{50}$ values, the number of potentially more specific effects increases, an aspect that will be discussed further, when the time dependence of effects will be considered (Tables 5, 6, 7, and 8).
At concentrations between $\mathrm{EC}_{50}$ and $\mathrm{LC}_{50}$, some observations were encountered at higher frequencies (Table 4). The most commonly observed endpoint was lordosis (12 compounds), followed by impaired heartbeat, pericardial edemata, and lack of hatching (10 compounds). Further, common endpoints include impaired heartbeat ( 9 compounds) and coagulation, lack of heartbeat, and craniofacial deformation $(8 \mathrm{com}$ pounds). In contrast, endpoints termed "more specific" in Table 4 were caused by a maximum of 2 compounds. Yolk edemata and impaired pigmentation were induced by 3 compounds, followed by impaired fin development (4 compounds).

Overall, frequencies of effects recorded between $\mathrm{EC}_{50}$ and $\mathrm{LC}_{50}$ are more diverse (3-100 \%) than frequencies of observation $\leq \mathrm{EC}_{50}$. As a rule, the number of effects between $\mathrm{EC}_{50}$ and $\mathrm{LC}_{50}$ is higher than at concentrations $\leq \mathrm{EC}_{50}$. Among the core OECD TG 236 endpoints, lack of heartbeat was most frequent (acrylamide, 50\%). For commonly observed nonOECD endpoints, few compounds exceeded $50 \%$ of individuals; again, paracetamol and valproic acid are exceptions (100 $\%$ ) for impaired/missing blood flow and reduced yolk resorption, respectively. Relatively high prevalence of changes in the circulatory system and edema indicate that these effects lose specificity with increasing test concentrations.

\section{Time and severity dependence of observations in the FET}

In contrast to a previous communication, which aimed at compiling a comprehensive and standardized catalog of observations in the FET test (von Hellfeld et al. 2020), the present study was designed to also analyze the onset and frequency (severity) of observations. Table 5 summarizes observations made at test concentrations $\leq \mathrm{EC}_{10}$. The "more specific 


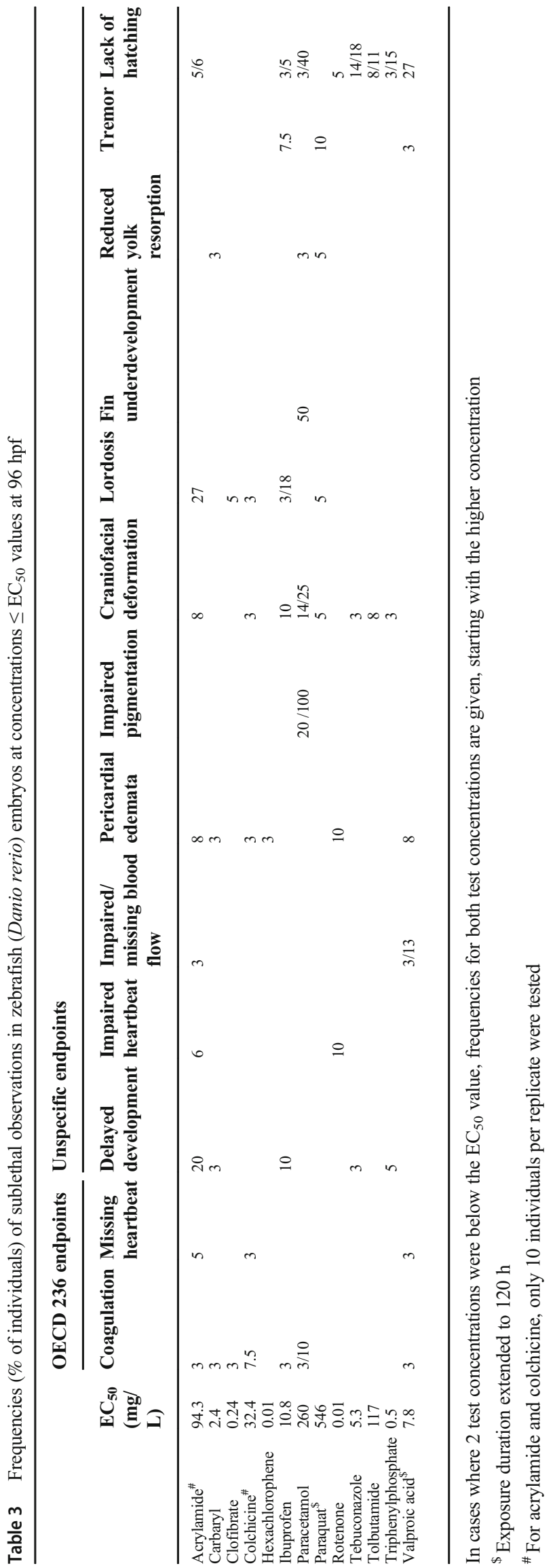

endpoints" found with only a low number of test compounds were considered as candidates for a fingerprint of toxicity, since these effects were indicative of the onset of compound-specific pathologies and were only rarely observed throughout the experiment. In fact, only 3 out of 7 "more specific" endpoints proved positive - all at very low frequencies and only showing up late (96-120 hpf). Likewise (and expectedly), OECD TG 236 core endpoints were also seen only rarely and at low frequencies. As a remarkable exception, colchicine exposure induced coagulation not only at the usual time point of $24 \mathrm{hpf}$, but also at later developmental stages (color code, 24-120 hpf).

The only endpoints induced at moderate frequency/ severity were craniofacial deformation and lordosis after exposure to hexachlorophene. All other observations were made at low frequencies, with colchicine and hexachlorophene inducing the highest number of effects (11 each). With respect to the developmental phase, the majority of endpoints positive at $\leq \mathrm{EC}_{10}$ was recorded at $\geq 48 \mathrm{hpf}$, and their partially transient nature was indicated by $80 \%$ of the observations only being present for one specific time point.

Table 6 compiles all observations recorded at $\leq \mathrm{EC}_{50}$ concentrations, including those listed in Table 5. With clofibrateinduced craniofacial deformation, the first observation with high severity/frequency (+++) is listed in Table 6. Out of the 84 observations recorded throughout this study, only 6 could be classified as moderately severe/frequent (++). Again, the majority of observations were made at $\geq 48 \mathrm{hpf}$, with only 30 listed for more than 1 time point.

Early developmental effects seen at $\leq \mathrm{EC}_{50}$ concentrations were coagulation (colchicine), lack of spontaneous movement (hexachlorophene, ibuprofen), and delayed development (hexachlorophene). At concentrations between $\mathrm{EC}_{10}$ and $\mathrm{EC}_{50}$ values, the number of effects by acrylamide increased by 9 . Valproic acid-exposed individuals were listed with 13 endpoints, as compared to 9 noted at $\leq \mathrm{EC}_{10}$ (Table 5). Ibuprofen exposure induced another 3 effects (one of which was considered more specific), followed by paracetamol, paraquat, and tolbutamide $(+2)$.

In contrast, only 3 out of the 6 endpoints listed for clofibrate $\leq \mathrm{EC}_{10}$ were seen between $\mathrm{EC}_{10}$ and $\mathrm{EC}_{50}$, with a general delay of development as a new endpoint. For carbaryl, clofibrate, hexachlorophene, and triphenylphosphate, no changes were seen with respect to the type and number of endpoints from $\leq \mathrm{EC}_{10}$ to $\leq \mathrm{EC}_{50}$. Since for rotenone both $\mathrm{EC}_{10}$ (Table 5) and $\mathrm{EC}_{50}$ values (Table 6) were extrapolated, no observations are listed in either table.

Table 7 lists all observations recorded up to $\mathrm{LC}_{10}$ concentrations. If compared to Table 6 and, even more so, Table 5, the number of and time span for observations increase signficantly. In fact, except for lack of spontaneous movement, which is, almost by definition, restricted to 


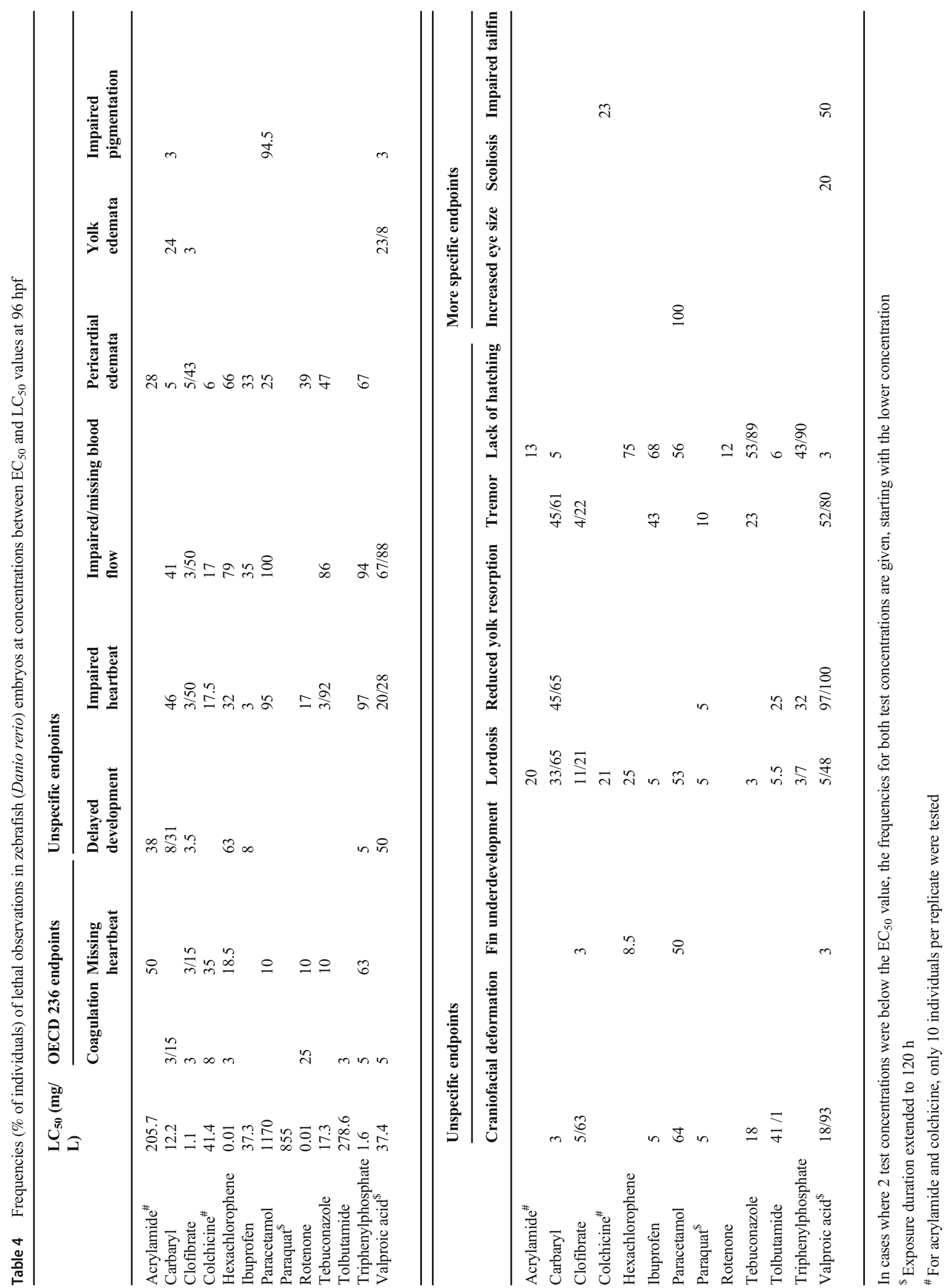


Table 5 Semi-quantitative evaluation of all effects in zebrafish (Danio rerio) embryos observed at $\leq \mathrm{EC}_{10}$ concentrations, grouped into lethal effects specified by OECD TG 236 (OECD 2013), unspecific alterations observed with most substances as well as "more specific" endpoints seen with $<4$ substances. Compounds organized alphabetically (observations from $n=2$ independent replicates)

\begin{tabular}{|c|c|c|c|c|c|c|c|c|c|c|c|c|c|c|c|c|c|c|c|c|c|c|c|c|c|c|c|c|}
\hline & & & $\overline{\mathrm{CD} 23}$ & $\overline{\text { endpo }}$ & & \multicolumn{16}{|c|}{ Unspecific endpoints } & \multicolumn{7}{|c|}{ More specific endpoints } \\
\hline Compound & $\begin{array}{c}\mathrm{EC}_{10} 96 \mathrm{~h} \\
(\mathrm{mg} / \mathrm{L})\end{array}$ & 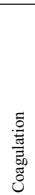 & 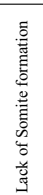 & 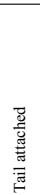 & 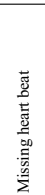 & 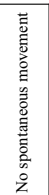 & 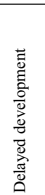 & 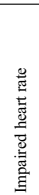 & 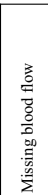 & 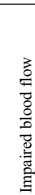 & 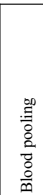 & 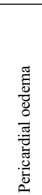 & 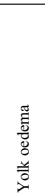 & 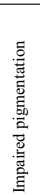 & 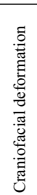 & 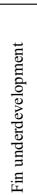 & $\begin{array}{l}\frac{n}{0} \\
\frac{8}{5} \\
\frac{8}{5}\end{array}$ & 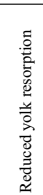 & 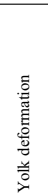 & 产 & 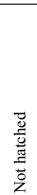 & 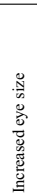 & 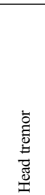 & 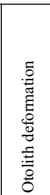 & 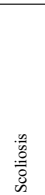 & 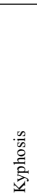 & 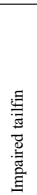 & 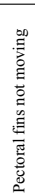 \\
\hline Acrylamide & 75.4 & & & & & & & & & & & & & & & & & & & & + & & & & & & & \\
\hline Carbaryl & 2.2 & & & & & & + & & & & & + & & & & & & + & & & & & & & & & & \\
\hline Clofibrate & 200 & & & & & & & + & & + & + & + & & & +4 & & + & & & & & & & & & & & \\
\hline Colchicine & 23.1 & + & & & + & & 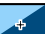 & +5 & +4 & +4 & + & + & + & & & & + & & & & & & & & & & + & \\
\hline Hexachlorophene & 0.004 & & & & & H & + & + & & + & + & $\$$ & + & + & + & & + & & & & 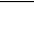 & & & & & + & & \\
\hline Ibuprofen & 4.7 & & & & & & & + & & + & + & + & + & & & & + & & & & + & & & & & & & \\
\hline Paracetamol & 200 & & & & & & & & & & & & + & & & & & & & & & & & & & & & \\
\hline Paraquat * & 400 & & & & & & & & + & + & + & + & & & & & + & & & & & & & & & & & \\
\hline Rotenone & 0.004 & & & & & & & & & & & & & & & & & & & & & & & & & & & \\
\hline $\begin{array}{l}\text { Tebuconazole } \\
\end{array}$ & 2.3 & & & & & & & & & & & & & & + & & & & & & + & & & & & & & \\
\hline Tolbutamide & 54.3 & & & & & & & & + & & + & & & & + & & & & & & + & & & & & & & \\
\hline Triphenylphosphate & 0.3 & & & & & & & & & & & & & & & & & & & & + & & & & & & & \\
\hline VPA * & 5.1 & & & & + & & & & & 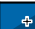 & th & + & + & + & & & & & & & & & & & + & & & \\
\hline
\end{tabular}

Effect intensity: + , rarely present and/or not severe; ++, frequently present and/or moderately severe; +++ , strong presence and/or high severity. Color codes: single-colored signatures indicate effects present from the time point indicated until the end of the experiment. Striped signatures indicate effects observed only between the two time points indicated by the colors

$24 \mathrm{hpf}$, most endpoints proved positive (i.e., persistent) over extended periods of development. Thus, with increasing concentration, endpoints of diverse nature gradually accumulate, making these endpoints less specific of the test substance. On the other hand, the number of "more specific endpoints" (seen with $<4$ substances) also increases. A conspicuous example of such "uncommon" observations is head tremor, which could only be seen after exposure to ibuprofen and tebuconazole. This endpoint has been speculated to be an indicator of reduced oxygen availability and has frequently been described as "gulping for air" (Huang et al. 2014). Usually, e.g., with paracetamol, but not necessarily, the severity of expression increases in parallel to test substance concentration and frequency of observations.

The trends seen in Table 7 find their continuation in Table 8: Most observations listed for test concentrations up to $\mathrm{LC}_{50}$ levels eventually lose all specificity. None of the test substances induced less than 8 endpoints, which was seen after expsoure to paraquat. In fact, hexachlorophene and valproic acid produced up to 18 different morphological effects in the extended FET test protocol; most interestingly, valproic acid also induced a total of 4 "more specific" endpoints, which was not expected at lethal concentrations close to $\mathrm{LC}_{50}$.

\section{Examples of substance-related effect profiles/specificity}

The most effect-specific compounds from the present compound list are seemingly carbaryl and triphenylphosphate, as they induced the same few endpoints at $\mathrm{EC}_{10}$ and $\mathrm{EC}_{50}$. While neither of these endpoints, at sublethal concentrations, were considered specific, the fact that even $\leq \mathrm{EC}_{50}$ for each of the compounds, no new endpoints became evident, this allows for the hypothesis that such endpoints are relatively compoundspecific and should be assessed in light of the compound's functioning and mechanisms of action.

Cabaryl The endpoints which can be observed at sublethal concentrations were delayed development, pericardial edemata, and reduced yolk resorption. Previous research showed that carbaryl competitively binds to melatonin receptors (Popovska-Gorevski et al. 2017), negatively affecting the overall metabolism as well as the circadian clock. Reduced yolk resorption was hypothesized to be caused by alterations in lipid metabolism and PPAR $\alpha$ expression levels (Weston et al. 2009; Coimbra et al. 2015; Kamstra et al. 2015). While in zebrafish embryos the liver is not fully formed (but active) before $72 \mathrm{hpf}$ (de Esch et al. 2012), endpoints relating to the yolk sac are nonetheless correlated to the hepatic system and thus hold the potential to indicate hepatotoxic compounds. Thus, the observation of both reduced yolk resorption and delayed development can be deemed to be indicators of the compound's effect on melatonin receptors. The development of pericardial edemata (with edemata being generally defined as a swelling of any body part due to fluid build-up; IQWiG 2016) is not fully understood. However, edemata observed in hexachlorophene-exposed mice proved to be only short-term effects and vanished after cessation of the treatment (Powell et al. 1973). It could thus be assumed that edemata, also 
Table 6 Semi-quantitative evaluation of all effects in zebrafish (Danio rerio) embryos observed at $\leq \mathrm{EC}_{50}$ concentrations, grouped into lethal effects specified by OECD TG 236 (OECD 2013), unspecific alterations observed with most substances, and "more specific" endpoints seen with $<4$ substances. Compounds organized alphabetically (observations from $n=2$ independent replicates)

\begin{tabular}{|c|c|c|c|c|c|c|c|c|c|c|c|c|c|c|c|c|c|c|c|c|c|c|c|c|c|c|c|c|}
\hline & & & $\mathrm{CD} 236$ & endpo & & \multicolumn{16}{|c|}{ Unspecific endpoints } & \multicolumn{7}{|c|}{ More specific endpoints } \\
\hline Compound & $\begin{array}{c}\mathrm{EC}_{50} 96 \mathrm{~h} \\
(\mathrm{mg} / \mathrm{L})\end{array}$ & 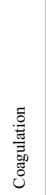 & 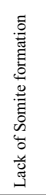 & 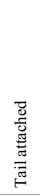 & 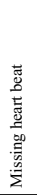 & 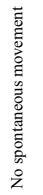 & 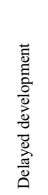 & 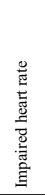 & 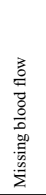 & 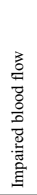 & 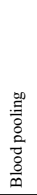 & 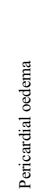 & 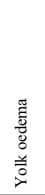 & 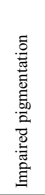 & 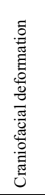 & 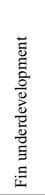 & $\begin{array}{l}\frac{n}{0} \\
\frac{50}{5} \\
\frac{5}{3}\end{array}$ & 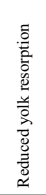 & 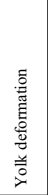 & 颜 & 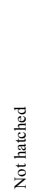 & 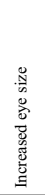 & 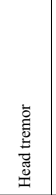 & 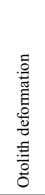 & 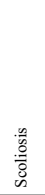 & 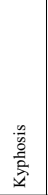 & 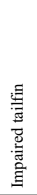 & 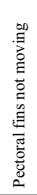 \\
\hline Acrylamide & 94.0 & & & & + & + & + & + & + & & + & + & & & + & & H & & & & + & & & & & & & \\
\hline Carbaryl & 2.4 & & & & & & + & & & & & + & & & & & & + & & & & & & & & & & \\
\hline Clofibrate & 300 & & & & & & & + & + & + & + & $H$ & & & +4 & & + & & & & & & & & & & & \\
\hline Colchicine & 32.4 & + & & & + & & 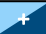 & + & + & + & + & + & + & & & & + & & & & & & & & & & + & \\
\hline Hexachlorophene & 0.005 & & & & & + & + & + & & + & + & + & + & + & + & & + & & & & . & & & & & + & & \\
\hline Ibuprofen & 10.8 & & & & & + & & + & & + & + & + & + & & & & + & & & & + & & + & & & & & \\
\hline Paracetamol & 300 & & & & & & & & & & & & + & +4 & + & & & & & & & & & & & & & \\
\hline Paraquat * & 500 & & & & & & & & + & + & + & + & & & + & & + & + & & + & & & & & & & & \\
\hline Rotenone & 0.007 & & & & & & & & & & & & & & & & & & & & & & & & & & & \\
\hline Tebuconazole & 5.3 & & & & & & + & & & & & & & & + & & & & & & + & & & & & & & \\
\hline Tolbutamide & 116.9 & & & & & & & & + & + & + & + & & & + & & & & & & + & & & & & & & \\
\hline Triphenylphosphate & 0.5 & & & & & & & & & & & & & & & & & & & & + & & & & & & & \\
\hline $\mathrm{VPA}^{*}$ & 7.8 & & & & + & & & + & + & + & + & + & + & + & + & & & + & & + & & & & & + & & & \\
\hline
\end{tabular}

Effect intensity: + , rarely present and/or not severe; ++, frequently present and/or moderately severe; +++, strong presence and/or high severity. Color codes: single-colored signatures indicate effects present from the time point indicated until the end of the experiment. Striped signatures indicate effects observed only between the two time points indicated by the colors

observed to be induced by the exposure to 6 other compounds $\leq \mathrm{EC}_{10}$, is an easily elicited response by the organisms which indicates an overall state of stress without being specifically linked to an underlying mechanism.

Triphenylphosphate The only endpoint that could be recorded at $\leq \mathrm{EC}_{50}$ for triphenylphosphate in the present study was the observation that embryos failed to hatch by $96 \mathrm{hpf}$ (controls, 72 hpf; Kimmel et al. 1995), which might be linked to the following two general pathologies: (1) First, the inability to hatch might be based on physical developmental delay, which already becomes evident in, e.g., the lack or delay of tail detachment at $24 \mathrm{hpf}$ (Kimmel et al. 1995). (2) Second, early spontaneous movement is thought to be an essential precoursor of hatching behavior (Xia et al. 2017). Embryonic behavioral endpoints such as coiling and swimming behavior have frequently been utilized to determine the developmental neurotoxic potential of compounds (Schmitt and Dowling 1999; Selderslaghs et al. 2010, 2013; Velki et al. 2017; Vliet et al. 2017; Ramlan et al. 2017; Basnet et al. 2019; Zindler et al. 2019b, a) and have successfully revealed alterations at sublethal concentrations. In the case of elevated (lethal) concentrations of triphenylphosphate (Tables 7 and 8), a multitude of unspecific endpoints including "tail non-detached," "delayed development," and "no spontaneous movement" could be listed and might be linked to either possible pathway of pathology. However, since the exposure failed to induce "tremor" as a further indicator of neurotoxicity (von Hellfeld et al. 2020), the observed lack of hatching at lower concentration was more likely due to developmental delays, which only become macroscopically visible at higher toxicant concentrations.

Acrylamide Acrylamide-exposed zebrafish expressed an inability to hatch at $\leq \mathrm{EC}_{10}$ as well as various circulatory defects (reduced heartbeat and impacted blood flow along with blood congestion) at sublethal concentrations, as well as delayed development and reduced hatching success. Previous studies found that acrylamide reduces the number of cardiomyocytes and their proliferative capacity, leading to morphological changes of the heart (Huang et al. 2018), thus impacting the general circulation and thus overall development. Whereas reduced heartbeat rates per se may not indicate direct pathology, considering it in correlation with endpoints such as reduced heart size or lack of heart looping, it may indicate a reduced proliferative capacity of the heart (Schock et al. 2012; Isales et al. 2015; Huang et al. 2018).

Colchicine Exposure to the mitosis inhibitor colchicine produced pronounced lordosis in zebrafish embryos. Colchicine generally affects cell division, which may easily explain the incorrect cell formation associated with lordosis and finally coagulation of the embryo (even at time points later than 24 hpf) at $\leq \mathrm{EC}_{10}$, as well as the impairment observed for tailfin development. In general, lordosis is also thought to be caused by alterations in the expression of the fibroblast growth factor, 
Table 7 Semi-quantitative evaluation of all effects in zebrafish (Danio rerio) embryos observed at $\leq \mathrm{LC}_{10}$ concentrations, grouped into lethal effects specified by OECD TG 236 (OECD 2013), unspecific alterations observed with most substances, and "more specific" endpoints seen with $<4$ substances. Compounds organized alphabetically (observations from $n=2$ independent replicates)

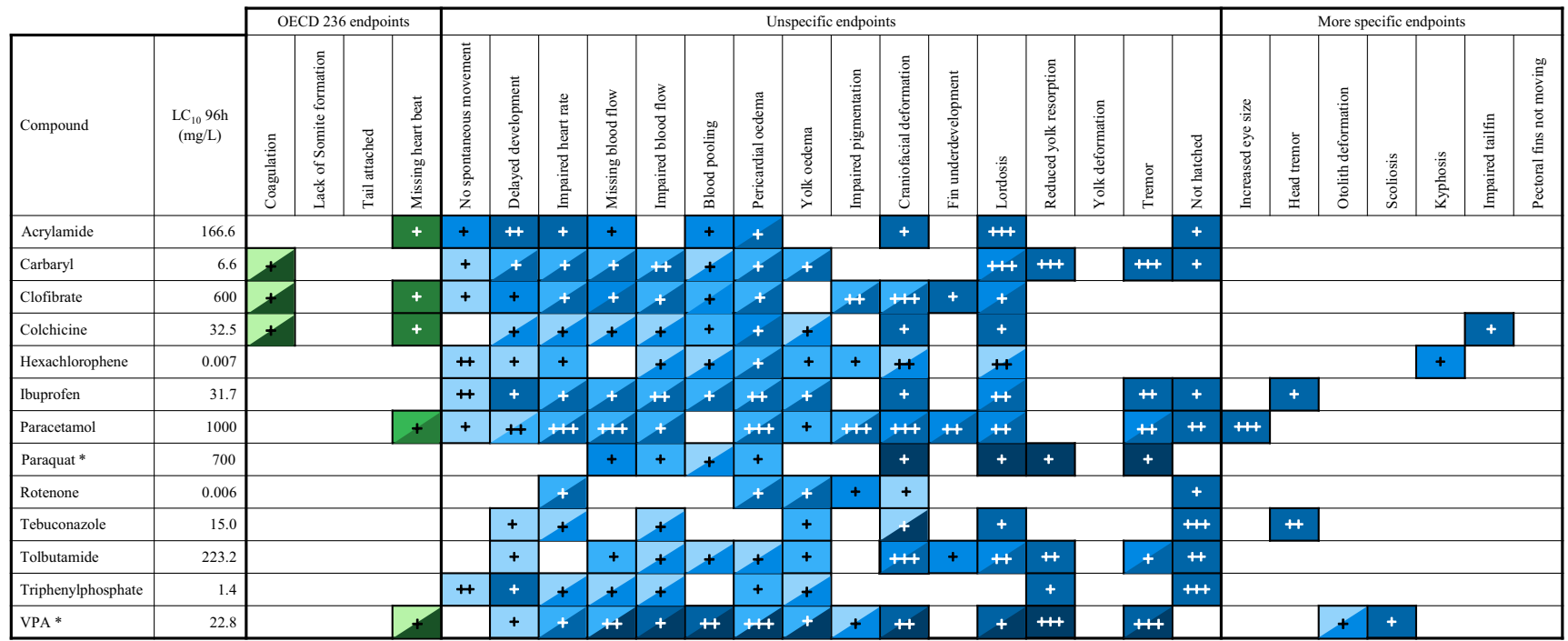

Effect intensity: + , rarely present and/or not severe; ++, frequently present and/or moderately severe; +++ , strong presence and/or high severity. Color codes: single-colored signatures indicate effects present from the time point indicated until the end of the experiment. Striped signatures indicate effects observed only between the two time points indicated by the colors

sonic hedgehog and bone morphogenetic protein, as well as Wnt and Notch genes (Lin 2002). The early onset of lordosis and coagulation at later developmental stages may thus seem specific of colchicine in the present study due to a combination of early pathways of developmental pathology.

Hexachlorophene Even at $\leq \mathrm{EC}_{10}$, hexachlorophene exposure induced kyphosis in the zebrafish embryos, along with various "unspecific" effects pertaining to the circulatory system, craniofacial formation, and lordosis. In contrast to lordosis as an inward concave curving of the cervical and lumbar regions of the spine, kyphosis is an abnormally excessive convex curvature of the spine especially in the thoracic and sacral regions. Kyphosis is thought to relate to myocyte degeneration and neural cell apoptosis (Kim et al. 2009). Hexachlorophene is a membrane channel inhibitor (Zheng et al. 2012), and it has been shown that the disruption of ion channel functionality plays a vital role in apoptosis (Kondratskyi et al. 2015), thus supporting the feasibility of kyphosis being more specific processes present in only certain cases. While the underlying pathways of spinal deformations such as lordosis, kyphosis, and scoliosis are yet to be fully elucidated, the differential observation of kyphosis, lordosis, and scoliosis (sideways curvature of the spine) offers an insight into potential pathways, which highlight the importance of correct identification and terminology of these endpoints due to their specificity (von Hellfeld et al. 2020).

Ibuprofen and tebuconazole Both of these compounds induced the "head tremor" endpoints, which have previously been linked to a "gulping for air"-like behavior (Huang et al. 2014). Ibuprofen is a PPAR $\alpha$ modulator and COX inhibitor (David and Pancharatna 2009a; Puhl et al. 2015) and induced the endpoint at $\leq \mathrm{EC}_{50}$, whereas tebuconazole, an inducer of oxidative stress, endocrine disruptor, and CYP450 inhibitor (Sancho et al. 2010; Yang et al. 2018) only did so at $\mathrm{LC}_{10}$ concentrations. Oxidative stress has previously been identified as both a cause for and a consequence of reduced oxygen availability in fish, leading to the increased gill movement or "gulping" observed in the present study. Studies have shown that nonsteroidal anti-inflammatory drugs (NSAIDs) such as ibuprofen increase the cardiac output in fish (Zhang et al. 2020 ), thus leading to an increased need for oxygen to sustain this behavior. Thus, although "head tremor" endpoint is not a frequent observation, it may well have two distinct underlying mechanisms.

Paracetamol The increased eye size following paracetamol exposure has been speculated to be caused by alterations in the retinoic acid pathway (Drummond and Davidson 2016), which is known to also induce heart deformations and damage to the retina (Isales et al. 2015). This led to the assumption that eye deformation, especially when observed along with heart deformation, indicates disruption of the retinoic pathway.

Valproic acid Exposure to valproic acid induced a total of four "more specific" endpoints: otolith deformation, scoliosis, impaired tailfin development, and the lack of pectoral fin movement. Valproic acid is a known histone deacetylase (HDAC) inhibitor, which is required for the 
Table 8 Semi-quantitative evaluation of all effects in zebrafish (Danio rerio) embryos observed at $\leq \mathrm{LC}_{50}$ concentrations, grouped into lethal effects specified by OECD TG 236 (OECD 2013), unspecific alterations observed with most substances as well as "more specific" endpoints seen with $<4$ substances. Compounds organized alphabetically (observations from $\mathrm{n}=2$ independent replicates)

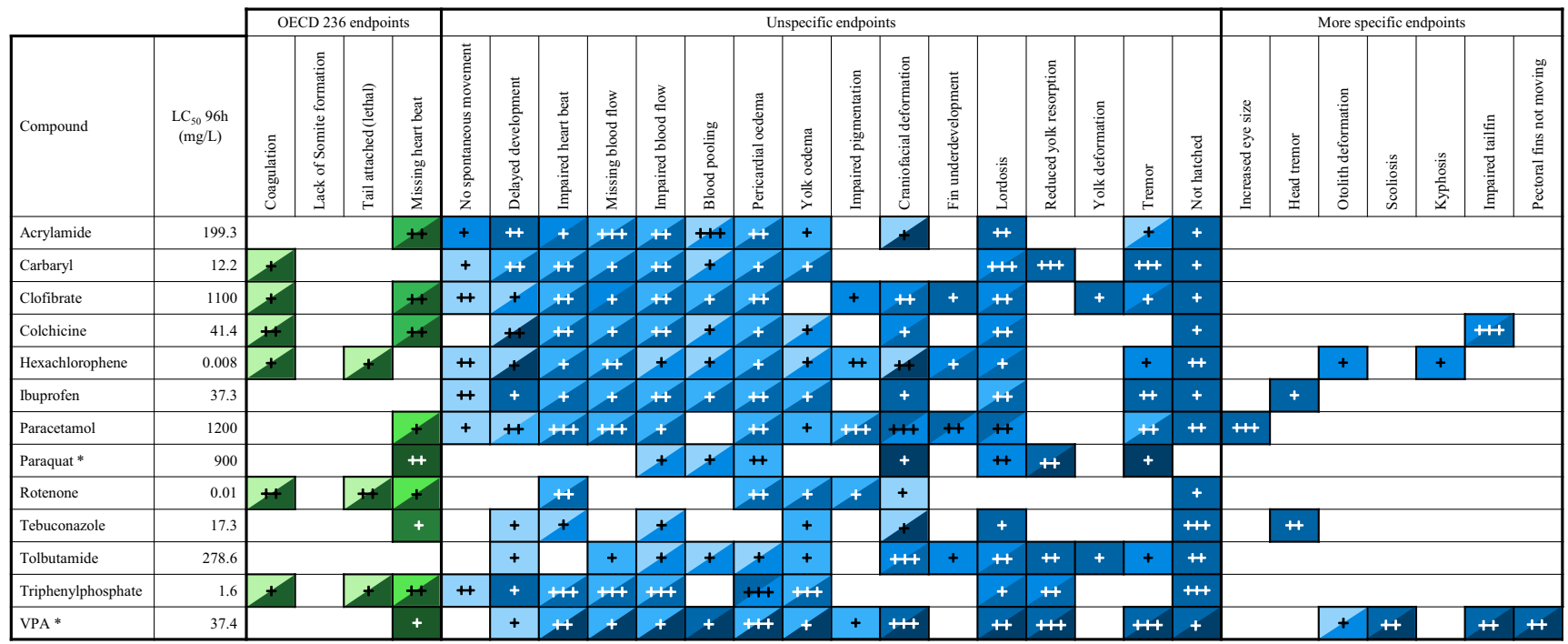

Effect intensity: + , rarely present and/or not severe; ++, frequently present and/or moderately severe; +++ , strong presence and/or high severity. Color codes: single-colored signatures indicate effects present from the time point indicated until the end of the experiment. Striped signatures indicate effects observed only between the two time points indicated by the colors

formation of the inner ear and other craniofacial structures (He et al. 2016), thus providing an explanation for the observation of otolith deformation. HDAC inhibition has further been linked to alterations in skeletal development in general and bone strength in mammals in particular. The inhibition of sirtuins (Bradley et al. 2015), a sub-group of HDAC enzymes, and HDAC2 (Tassano et al. 2015) in particular are known for inducing spinal curvature defects such as scoliosis. Further studies revealed that HDAC8 inhibition leads to smaller hands and feet in humans (Deardorff et al. 2012; Kaiser et al. 2014), while HDAC4 inhibition induced shortened metatarsals and metacarpals (Williams et al. 2010; Villavicencio-Lorini et al. 2013). While all these findings are based on humans and other terrestrial mammals, the genetic homology of zebrafish allows for the consideration that these underlying functions of the different HDACs are comparable to at least a certain degree, thus possibly explaining the unique tail and pectoral fin alterations observed in the present study.

\section{Time-dependent toxicity profile}

Out of the compounds tested in the present study, only acrylamide and colchicine expressed a statistically significant modulation of $\mathrm{LC}$ values over exposure time (Fig. 1). The $\mathrm{LC}_{50}$ of acrylamide significantly decreased between 48 and $96 \mathrm{hpf}$, with significant differences between each of the three time points tested $(\rho=0.034)$. In contrast, $\mathrm{LC}_{10}$ values for either substance did not show any significant impact over time, although there was a clear trend for colchicine: For individuals exposed to colchicine, the $\mathrm{LC}_{50}$ also varied significantly between 48 and $96 \mathrm{hpf}(\rho=0.019)$, yet without a significant difference between 48 and $72 \mathrm{hpf}$ or 72 and $96 \mathrm{hpf}$.

The fish embryo test with the zebrafish embryo is conducted during a period of rapid development and, thus, massive time-dependent changes (Kimmel et al. 1995). Chemical compounds may affect mechanisms or organs, which have not fully developed: Hepatotoxic compounds, e.g., can only express their impact after $72 \mathrm{~h}$ of exposure, when the liver becomes functional. The full toxic potential on the zebrafish embryo, however, will likely unfold after $120 \mathrm{hpf}$, when the liver has reached full functionality and a certain volume (de Esch et al. 2012). This may, in part, provide an explanation why the toxicity of, e.g., valproic acid shows an increase over the entire exposure duration (Dai et al. 2015).

Another important consideration with respect to the time dependence of both morphological and functional effects is the potential barrier function of the chorion in combination with limited absorption rate and poor membrane permeability for certain compounds such as colchicine (Brox et al. 2016). As a consequence, a delay in the expression of toxicity may develop, which, however, can rapidly be compensated upon hatching (Roche et al. 1994; Henn and Braunbeck 2011). However, it should be noted that the barrier function of the chorion plays a less important role (Zhang and Rawsom 1996; Kais et al. 2013; Braunbeck et al. 2020) than originally postulated (Hagedorn et al. 1997, 1998; Adams et al. 2005). In line with the developmental time line, the nervous system is assumed to be fully developed only by 10 days postfertilization (de Esch et al. 2012). This implies that in case 


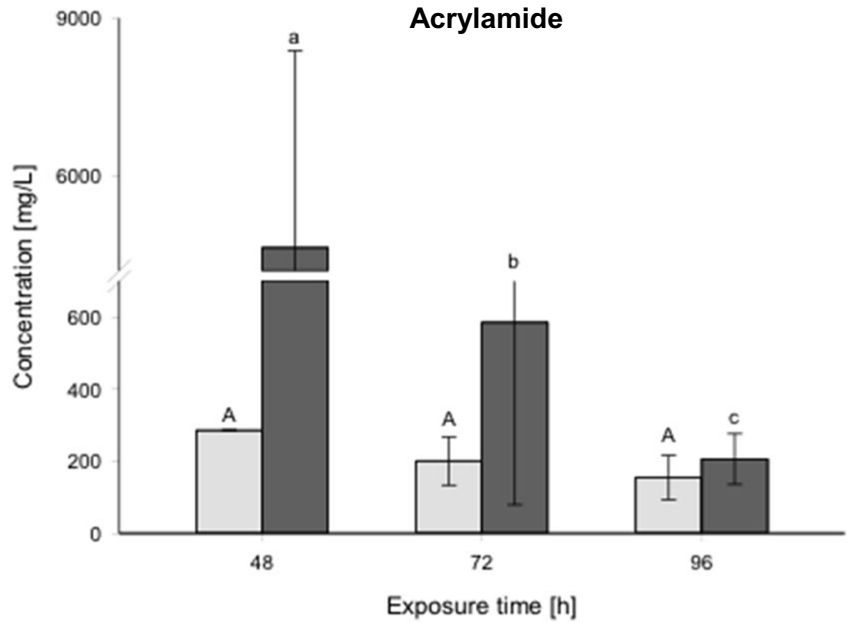

Fig. 1 Time course of the toxicity of acrylamide (a) and colchicine (b) to embryos of zebrafish (Danio rerio) over $96 \mathrm{~h}$ according to OECD TG 236 $(n=4)$. Statistical significance is indicated by lowercase letters between

compounds tested in the FET test are likely to induce severe neurodevelopmental effects, only part of the endpoints of neurotoxicity may be observable in 96-h-old embryos (Zindler et al. 2019a, b, 2020a, b). For some endpoints (such as swimming assays and anxiety tests), specific test setups might be required (Selderslaghs et al. 2009, 2012, 2013; Zindler et al. 2019a, 2020a, b).

\section{Conclusions}

The present study aimed to differentiate between endpoints indicative of general or more specific pathologies. In any case, the present analysis of endpoints provides clear evidence that the fish embryo acute toxicity (FET) test can provide significantly more detailed information about the test compounds than originally planned for the OECD guideline 236 . By the addition of an open list of further endpoints to the core observations specified by the original OECD guideline, the present communication was able to develop different endpoint profiles for the test compounds, even though the final "adverse outcome" of various pathways might ultimately be the same. Although a quite rudimentary type of "toxicity fingerprinting", the syndrome originating from the collection of a full set of observations may well be of interest for regulatory purposes in terms of defining environmentally relevant threshold values. In combination with in-depth literature analysis, the present study also documents the usefulness of the FET for the development adverse outcome pathways (AOPs) for specific (classes of) test compounds. Based on the numerous advantages of the zebrafish as a test organism, and given its simplicity, versatility, reproducibility, and complementarity with other systems, the FET test has received increasing attention over many years and will continue to do so. However, future

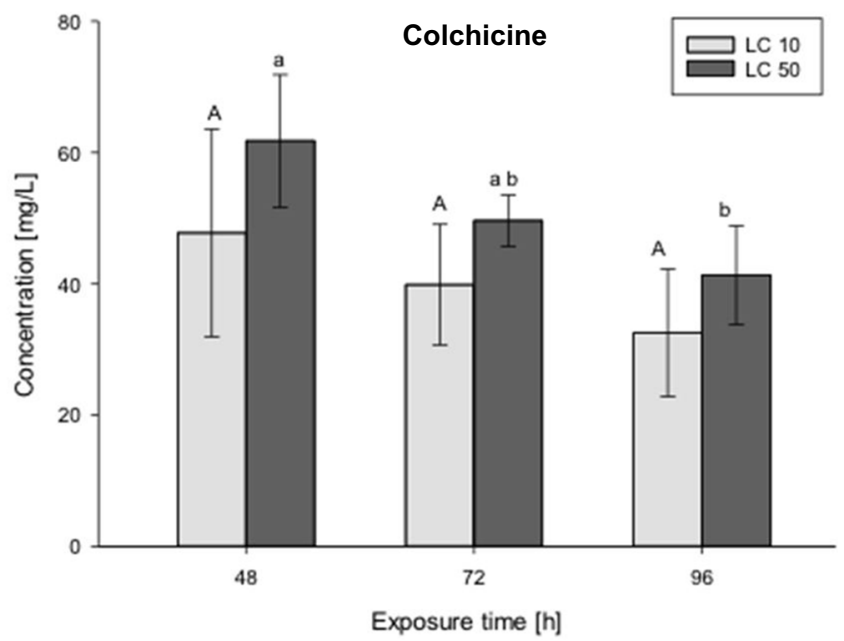

time points (acrylamide: $\rho=0.034$; colchicine: $\rho=0.019$ ); identical capital letters indicate no statistically significant difference between time points

research would benefit greatly from the creation of a FET test endpoint database, allowing the comparison of effects, and from the use of a unified scoring system. An established, comprehensive nomenclature for different endpoints would make results obtained from different laboratories more comparable and allow for not only a more conclusive interpretation, but also a more in-depth understanding of observations.

Supplementary Information The online version contains supplementary material available at https://doi.org/10.1007/s11356-021-16354-4.

Acknowledgements This project has received funding from the European Union's Horizon 2020 research and innovation program under grant agreement No 681002 (GA, art. 38.1.2). The raw data for valproic acid, acrylamide, and colchicine were provided by Katharina Brotzmann, Annika Batel, and Ann-Kathrin Lörracher, respectively. Range-finding experiments were previously also conducted by Susanna Mieck, Dr. Lisa Hanslik, and Dr. Florian Zindler. Thanks are due to Jonathan Griffiths and Christoph Gade for carefully editing parts of the manuscript.

Author contribution RH conduced the experiments, analyzed the data, created the figures and tables, and drafted the manuscript. PP and TB contributed to the layout of the tables and repeatedly reviewed the manuscript. TB provided funding and laboratory facilities. All of the authors read and approved the final manuscript.

Funding Open Access funding enabled and organized by Projekt DEAL. This project has received funding from the European Union's Horizon 2020 research and innovation program under the grand agreement No 681002.

Data availability Original datasets of the current study and analyses generated are available in the BioStudies repository (https://wwwdev.ebi.ac. uk/biostudies/EU-ToxRisk/).

\section{Declarations}

Ethics approval and consent to participate Not applicable.

Consent for publication Not applicable. 
Competing interests The authors declare no competing interests.

\section{References}

Adams SL, Zhang T, Rawson DM (2005) The effect of external medium composition on membrane water permeability of zebrafish (Danio rerio) embryos. Theriogenology 64:1591-1602. https://doi.org/10. 1016/j.theriogenology.2005.03.018

Ali S, van Mil HGJ, Richardson MK (2011) Large-scale assessment of the zebrafish embryo as a possible predictive model in toxicity testing. PLoS One 6:e21076. https://doi.org/10.1371/journal.pone. 0021076

Andreozzi R, Marotta R, Paxéus N (2003) Pharmaceuticals in STP effluents and their solar photodegradation in aquatic environment. Chemosphere 50:1319-1330. https://doi.org/10.1016/S00456535(02)00769-5

Bambino K, Chu J (2017) Zebrafish in toxicology and environmental health. In: Current Topics in Developmental Biology. pp 331-367, Zebrafish in Toxicology and Environmental Health

Basnet R, Zizioli D, Taweedet S, Finazzi D, Memo M (2019) Zebrafish larvae as a behavioral model in neuropharmacology. Biomedicines 7:23. https://doi.org/10.3390/biomedicines 7010023

Behra M (2004) The use of zebrafish mutants to identify secondary target effects of acetylcholine esterase inhibitors. Toxicol Sci 77:325-333. https://doi.org/10.1093/toxsci/kfh020

Bradley EW, Carpio LR, van Wijnen AJ, McGee-Lawrence ME, Westendorf JJ (2015) Histone deacetylases in bone development and skeletal disorders. Physiol Rev 95:1359-1381. https://doi.org/ 10.1152/physrev.00004.2015

Brannen KC, Panzica-Kelly JM, Danberry TL, Augustine-Rauch KA (2010) Development of a zebrafish embryo teratogenicity assay and quantitative prediction model. Birth Defects Res Part B Dev Reprod Toxicol 89:66-77. https://doi.org/10.1002/bdrb.20223

Braunbeck T (2009) Zebrafish embryos as a model in general toxicology. Toxicol Lett 189:S48-S49. https://doi.org/10.1016/j.toxlet.2009.06. 097

Braunbeck T, Boettcher M, Hollert $\mathrm{H}$ et al (2005) Towards an alternative for the acute fish $\mathrm{LC}(50)$ test in chemical assessment: the fish embryo toxicity test goes multi-species - an update. ALTEX Altern zu Tierexperimenten 22:87-102. https://doi.org/10.1007/s10811-0079297-x

Braunbeck T, Böhler S, Knörr S, et al (2020) Development of an OECD guidance document for the application of OECD test guideline 236 (acute fish embryo toxicity test): the chorion structure and biotransformation capacities of zebrafish as boundary conditions for OECD test guideline 236. UBA Texte 94:106 pp.

Braunbeck T, Kais B, Lammer E, Otte J, Schneider K, Stengel D, Strecker R (2015) The fish embryo test (FET): origin, applications, and future. Environ Sci Pollut Res Int 22:16247-16261. https://doi. org/10.1007/s11356-014-3814-7

Brito DA, Yang Z, Rieder CL (2008) Microtubules do not promote mitotic slippage when the spindle assembly checkpoint cannot be satisfied. J Cell Biol 182(4):623-629. https://doi.org/10.1083/jcb. 200805072

Brox S, Seiwert B, Küster E, Reemtsma T (2016) Toxicokinetics of polar chemicals in zebrafish embryo (Danio rerio): influence of physicochemical properties and of biological processes. Environ Sci Technol 50:10264-10272. https://doi.org/10.1021/acs.est.6b04325

Bundesgesetzblatt (2005) Bekanntmachung der Neufassung des Abwasserabgabegesetzes. Teil I, Nr. 5. Bonn

CEFIC (2021) 2021 Facts and figures of the European chemical market. In: Our ind. https://cefic.org/our-industry/a-pillar-of-the-europeaneconomy/facts-and-figures-of-the-european-chemical-industry/
Chateauvieux S, Morceau R, Dicato M, Diederich M (2010) Molecular and therapeutic potential and toxicity of valproic acid. J Biomed Biotechnol 2010:1-18. https://doi.org/10.1155/2010/479364

Cheng WW, Farrell AP (2007) Acute and sublethal toxicities of rotenone in juvenile rainbow trout (Oncorhynchus mykiss): swimming performance and oxygen consumption. Arch Environ Contam Toxicol 52(3):388 396. https://doi.org/10.1007/s00244-006-0051-1

Christou M, Kavaliauskis A, Ropstad E, Fraser TWK (2020) DMSO effects larval zebrafish (Danio rerio) behavior, with additive and interaction effects when combined with positive controls. Sci Total Environ 709:134490. https://doi.org/10.1016/j.scitotenv.2019. 134490

Coimbra AM, Peixoto MJ, Coelho I, Lacerda R, Carvalho AP, Gesto M, Lyssimachou A, Lima D, Soares J, André A, Capitão A, Castro LFC, Santos MM (2015) Chronic effects of clofibric acid in zebrafish (Danio rerio): a multigenerational study. Aquat Toxicol 160:76-86. https://doi.org/10.1016/j.aquatox.2015.01.013

Dai W, Wang K, Zheng X, Chen X, Zhang W, Zhang Y, Hou J, Liu L (2015) High fat plus high cholesterol diet lead to hepatic steatosis in zebrafish larvae: a novel model for screening anti-hepatic steatosis drugs. Nutr Metab (Lond) 12:42-53. https://doi.org/10.1186/ s12986-015-0036-Z

Dang Z, Kienzler A (2019) Changes in fish sex ratio as a basis for regulating endocrine disruptors. Environ Int 130:104928. https://doi.org/ 10.1016/j.envint.2019.104928

David A, Pancharatna K (2009) Developmental anomalies induced by a non-selective COX inhibitor (ibuprofen) in zebrafish (Danio rerio). Environ Toxicol Pharmacol 27:390-395. https://doi.org/10.1016/j. etap.2009.01.002

David A, Pancharatna K (2009b) Effects of acetaminophen (paracetamol) in the embryonic development of zebrafish, Danio rerio. J Appl Toxicol 29(7):597-602. https://doi.org/10.1002/jat.1446

De Esch C, Slieker R, Wolterbeek A et al (2012) Zebrafish as potential model for developmental neurotoxicity testing. A mini review. Neurotoxicol Teratol 34:545-553. https://doi.org/10.1016/j.ntt. 2012.08.006

Deardorff MA, Bando M, Nakato R, Watrin E, Itoh T, Minamino M, Saitoh K, Komata M, Katou Y, Clark D, Cole KE, de Baere E, Decroos C, di Donato N, Ernst S, Francey LJ, Gyftodimou Y, Hirashima K, Hullings M et al (2012) HDAC8 mutations in Cornelia de Lange syndrome affect the cohesin acetylation cycle. Nature 489:313-317. https://doi.org/10.1038/nature11316

Den Broeder MJ, Kopylova VA, Kamminga LM, Legler J (2015) Zebrafish as a model to study the role of peroxisome proliferatingactivated receptors in adipogenesis and obesity. PPAR Res 2015:111. https://doi.org/10.1155/2015/358029

Dhillon GS, Kaur S, Pulicharla R, Brar S, Cledón M, Verma M, Surampalli R (2015) Triclosan: current status, occurrence, environmental risks and bioaccumulation potential. Int J Environ Res Public Health 12:5657-5684. https://doi.org/10.3390/ijerph120505657

Dix DJ, Houck KA, Martin MT, Richard AM, Setzer RW, Kavlock RJ (2007) The toxcast program for prioritizing toxicity testing of environmental chemicals. Toxicol Sci 95:5-12. https://doi.org/10.1093/ toxsci/kfl103

Driessen M, Kienhuis AS, Pennings JLA, Pronk TE, van de Brandhof EJ, Roodbergen M, Spaink HP, van de Water B, van der Ven LTM (2013) Exploring the zebrafish embryo as an alternative model for the evaluation of liver toxicity by histopathology and expression profiling. Arch Toxicol 87:807-823. https://doi.org/10.1007/ s00204-013-1039-z

Drummond IA, Davidson AJ (2016) Zebrafish kidney development. Methods in cell biology, third edit. Elsevier Inc., In, pp 391-429

Du K, Ramachandran A, Jaeschke H (2016) Oxidative stress during acetaminophen hepatotoxicity: sources pathophysiological role and therapeutic potential. Redox Biol 10:148-156. https://doi.org/10. 1016/j.redox.2016.10.001 
EC (2020) 2019 report on the statistics on the number of animals used for experimental and other scientific purposes in the member states of the European union in 2015-2017. Commission staff working document

EU (2007) Regulation (EC) No 1907/2006 of the European Parliament and of the council of 18 December 2006 concerning the Registration, Evaluation, Authorisation and Restriction of Chemicals (REACH), establishing a European Chemicals Agency, amending Directive 1999/4

EU (2010) Directive 2010/63/EU of the European parliament and of the counsil of 22 September 2010 on the protection of animals used for scientific purposes

Eurostat (2020) Production and consumption of chemicals by hazard class. In: Eurostat Stat. Explain. https://ec.europa.eu/eurostat/ statistics-explained/index.php?title $=$ Chemicals production and consumption statistics\&oldid $=493630$

Faria M, Ziv T, Gómez-Canela C, Ben-Lulu S, Prats E, Novoa-Luna KA, Admon A, Piña B, Tauler R, Gómez-Oliván LM, Raldúa D (2018) Acrylamide acute neurotoxicity in adult zebrafish. Sci Rep 8(1). https://doi.org/10.1038/s41598-018-26343-2

Fernandes Y, Buckley DM, Eberhart JK (2018) Diving into the world of alcohol teratogenesis: a review of zebrafish models of fetal alcohol spectrum disorder. Biochem Cell Biol 96:88-97. https://doi.org/10. 1139/bcb-2017-0122

Fulton MH, Key PB (2001) Acetylcholinesterase inhibition in estuarine fish and invertebrates as an indicator of organophosphorus insecticide exposure and effects. Environ Toxicol Chem 20:37-45. https:// doi.org/10.1002/etc.5620200104

Gagné F, André C, Turcotte P, Gagnon C, Sherry J, Talbot A (2013) A comparative toxicogenomic investigation of oil sand water and processed water in rainbow trout hepatocytes. Arch Environ Contam Toxicol 65:309-323. https://doi.org/10.1007/s00244-0139888-2

Gohdke-Puranik Y, Thorn CF, Lamba JK, Leeder JS, Song W, Birnbaum AK, Altman RB, Klein TE (2013) Valproic acid pathway: Pharmacogenetics and pharmacodynamics. Pharmacogenet Genomics 23(4):236-241. https://doi.org/10.1097/FPC. $0 \mathrm{~b} 013 \mathrm{e} 32835 \mathrm{ea} 0 \mathrm{~b} 2$

Green AJ, Planchart A (2018) The neurological toxicity of heavy metals: a fish perspective. Comp Biochem Physiol Part C Toxicol Pharmacol 208:12-19. https://doi.org/10.1016/j.cbpc.2017.11.008

Guo P, Huang Z, Tao T, Chen X, Zhang W, Zhang Y, Lin C (2015) Zebrafish as a model for studying the developmental neurotoxicity of propofol. J Appl Toxicol 35:1511-1519. https://doi.org/10.1002/ jat.3183

Hagedorn M, Kleinhans FW, Artemov D, Pilatus U (1998) Characterization of a major permeability barrier in the zebrafish embryo. Biol Reprod 59:1240-1250. https://doi.org/10.1095/ biolreprod59.5.1240

Hagedorn M, Kleinhans FW, Wildt DE, Rall WF (1997) Chill sensitivity and cryoprotectant permeability of dechorionated zebrafish embryos, Brachydanio rerio. Cryobiology 34:251-263. https://doi.org/10. 1006/cryo.1997.2002

Hartung T, Rovida C (2009) Chemical regulators have overreached. Nature 460:1080-1081. https://doi.org/10.1038/4601080a

He Y, Tang D, Li W, Chai R, Li H (2016) Histone deacetylase 1 is required for the development of the zebrafish inner ear. Sci Rep 6: 1-16. https://doi.org/10.1038/srep16535

Henn K, Braunbeck T (2011) Dechorionation as a tool to improve the fish embryo toxicity test (FET) with the zebrafish (Danio rerio). Comp Biochem Physiol - C Toxicol Pharmacol 153:91-98. https://doi.org/ 10.1016/j.cbpc.2010.09.003

Hong YL, Hossler PA, Calhoun DH, Meshnick SR (1995) Inhibition of recombinant pneumocystis carinii dihydropteroate synthetase by sulfa drugs. Antimicrob Agents Chemother 39(8):1756-1763. https://doi.org/10.1128/AAC.39.8.1756
Hrovat M, Segner H, Jeram S (2009) Variability of in vivo fish acute toxicity data. Regul Toxicol Pharmacol 54:294-300. https://doi. org/10.1016/j.yrtph.2009.05.013

Huang M, Jiao J, Wang J, Xia Z, Zhang Y (2018) Characterization of acrylamide-induced oxidative stress and cardiovascular toxicity in zebrafish embryos. J Hazard Mater 347:451-460. https://doi.org/10. 1016/j.jhazmat.2018.01.016

Huang Y, Zhang J, Han X, Huang T (2014) The use of zebrafish (Danio rerio) behavioral responses in identifying sublethal exposures to deltamethrin. Int J Environ Res Public Health 11:3650-3660. https://doi.org/10.3390/ijerph110403650

IQWiG (2016) Institute for quality and efficiency in health care: causes and signs of edema. In: InformedHealth.org. https://www.ncbi.nlm. nih.gov/books/NBK279409/. Accessed 12 Oct 2020

Isales GM, Hipszer RA, Raftery TD, Chen A, Stapleton HM, Volz DC (2015) Triphenyl phosphate-induced developmental toxicity in zebrafish: potential role of the retinoic acid receptor. Aquat Toxicol 161:221-230. https://doi.org/10.1016/j.aquatox.2015.02. 009

ISO (2007) International standard water quality - determination of the acute toxicity of waste water to zebrafish eggs (Danio rerio)

ISO (1996) ISO 7346 - Water quality - Determination of the acute lethal toxicity of substances to a freshwater fish [Brachydanio rerio Hamilton-Buchanan (Teleostei, Cyprinidae)] - Part 1: Static method; Part 2: Semi-static method

Jesús A, Serrano L, Maccioni RB (1987) Regulatory aspects of the colchicine interactions with tubulin. Mol Cell Biochem 73(1). https:// doi.org/10.1007/BF00229373

Kais B, Schneider KE, Keiter S, Henn K, Ackermann C, Braunbeck T (2013) DMSO modifies the permeability of the zebrafish (Danio rerio) chorion-implications for the fish embryo test (FET). Aquat Toxicol 140-141:229-238. https://doi.org/10.1016/j.aquatox.2013. 05.022

Kais B, Stengel D, Batel A, Braunbeck T (2015) Acetylcholinesterase in zebrafish embryos as a tool to identify neurotoxic effects in sediments. Environ Sci Pollut Res 22:16329-16339. https://doi.org/10. 1007/s11356-014-4014-1

Kaiser FJ, Ansari M, Braunholz D, Concepción Gil-Rodríguez M, Decroos C, Wilde JJ, Fincher CT, Kaur M, Bando M, Amor DJ, Atwal PS, Bahlo M, Bowman CM, Bradley JJ, Brunner HG, Clark D, del Campo M, di Donato N, Diakumis P et al (2014) Loss-offunction HDAC8 mutations cause a phenotypic spectrum of Cornelia de Lange syndrome-like features, ocular hypertelorism, large fontanelle and X-linked inheritance. Hum Mol Genet 23: 2888-2900. https://doi.org/10.1093/hmg/ddu002

Kamstra JH, Aleström P, Kooter JM, Legler J (2015) Zebrafish as a model to study the role of DNA methylation in environmental toxicology. Environ Sci Pollut Res 22:16262-16276. https://doi.org/10. 1007/s11356-014-3466-7

Kim D-J, Seok S-H, Baek M-W, Lee HY, Na YR, Park SH, Lee HK, Dutta NK, Kawakami K, Park JH (2009) Developmental toxicity and brain aromatase induction by high genistein concentrations in zebrafish embryos. Toxicol Mech Methods 19:251-256. https://doi. org $/ 10.1080 / 15376510802563330$

Kimmel C, Ballard W, Kimmel S et al (1995) Stages of embryonic development of the zebrafish. Am J Anat 203:253-310

Kondratskyi A, Kondratska K, Skryma R, Prevarskaya N (2015) Ion channels in the regulation of apoptosis. Biochim Biophys Acta Biomembr 1848:2532-2546. https://doi.org/10.1016/j.bbamem. 2014.10.030

Küster A, Adler N (2014) Pharmaceuticals in the environment: scientific evidence of risks and its regulation. Philos Trans R Soc B Biol Sci 369:20130587. https://doi.org/10.1098/rstb.2013.0587

Lammer E, Carr GJ, Wendler K, Rawlings JM, Belanger SE, Braunbeck $\mathrm{T}$ (2009) Is the fish embryo toxicity test (FET) with the zebrafish (Danio rerio) a potential alternative for the fish acute toxicity test? 
Comp Biochem Physiol - C Toxicol Pharmacol 149:196-209. https://doi.org/10.1016/j.cbpc.2008.11.006

Laville N, Ait-Aïssa S, Gomez E, Casellas C, Porcher J M (2004) Effects of human pharmaceuticals on cytotoxicity EROD activity and ROS production in fish hepatocytes. Toxicology 196(1-2):41-55. https:// doi.org/10.1016/j.tox.2003.11.002

Li X, Zhang B, Li N, Ji X, Liu K, Jin M (2019) Zebrafish neurobehavioral phenomics applied as the behavioral warning methods for fingerprinting endocrine disrupting effect by lead exposure at environmentally relevant level. Chemosphere 231:315-325. https://doi.org/10. 1016/j.chemosphere.2019.05.146

Lin S (2002) The zebrafish as a model for human disease. Front Biosci 7: A851-d1453. https://doi.org/10.2741/A851

Lisse TS, Middleton LJ, Pellegrini AD, Martin PB, Spaulding EL, Lopes O, Brochu EA, Carter EV, Waldron A, Rieger S (2016) Paclitaxelinduced epithelial damage and ectopic MMP-13 expression promotes neurotoxicity in zebrafish. Proc Natl Acad Sci 113(15): E2189-E2198. https://doi.org/10.1073/pnas.1525096113

Liu X, Jung D, Jo A, Ji K, Moon H-B, Choi K (2016) Long-term exposure to triphenylphosphate alters hormone balance and HPG, HPI, and HPT gene expression in zebrafish (Danio rerio). Environ Toxicol Chem 35(9):2288-2296. https://doi.org/10.1002/etc.3395

Llansola M, Montoliu C, Boix J, Felipo V (2009) Polychlorinated biphenyls PCB 153 and PCB 126 impair the glutamate-nitric oxidecGMP pathway in cerebellar neurons in culture by different mechanisms. Neurotox Res 16(2):97-105. https://doi.org/10.1007/ s12640-009-9055-8

Lushchak VI (2016) Contaminant-induced oxidative stress in fish: a mechanistic approach. Fish Physiol Biochem 42(2):711-747. https://doi.org/10.1007/s10695-015-0171-5

Maes J, Verlooy L, Buenafe OE, de Witte PAM, Esguerra CV, Crawford AD (2012) Evaluation of 14 organic solvents and carriers for screening applications in zebrafish embryos and larvae. PLoS One 7:1-9. https://doi.org/10.1371/journal.pone.0043850

Mahatthanatrakul W, Nontaput T, Ridtitid W, Wongnawa M, Sunbhanich M (2007) Rifampin a cytochrome P450 3A inducer decreases plasma concentrations of antipsychotic risperidone in healthy volunteers. J Clin Pharm Ther 32(2):161-167. https://doi. org/10.1111/j.1365-2710.2007.00811.x

Matthiessen P, Wheeler JR, Weltje L (2018) A review of the evidence for endocrine disrupting effects of current-use chemicals on wildlife populations. Crit Rev Toxicol 48:195-216. https://doi.org/10. 1080/10408444.2017.1397099

Nagel R (2002) DarT: The embryo test with the Zebrafish Danio rerio-a general model in ecotoxicology and toxicology. ALTEX Altern zu Tierexperimenten 19:38-48

Neale PA, Altenburger R, Aït-Aïssa S, Brion F, Busch W, de Aragão Umbuzeiro G, Denison MS, du Pasquier D, Hilscherová K, Hollert H, Morales DA, Novák J, Schlichting R, Seiler TB, Serra H, Shao Y, Tindall AJ, Tollefsen KE, Williams TD, Escher BI (2017) Development of a bioanalytical test battery for water quality monitoring: fingerprinting identified micropollutants and their contribution to effects in surface water. Water Res 123:734-750. https://doi. org/10.1016/j.watres.2017.07.016

Nendza M, Wenzel A (2006) Discriminating toxicant classes by mode of action - 1. (Eco)toxicity profiles. Environ Sci Pollut Res Int 13:192203. https://doi.org/10.1065/espr2006.01.013

Nishimura Y, Inoue A, Sasagawa S, Koiwa J, Kawaguchi K, Kawase R, Maruyama T, Kim S, Tanaka T (2016) Using zebrafish in systems toxicology for developmental toxicity testing. Congenit Anom (Kyoto) 56:18-27. https://doi.org/10.1111/cga.12142

Nishimura Y, Murakami S, Ashikawa Y, Sasagawa S, Umemoto N, Shimada Y, Tanaka T (2015) Zebrafish as a systems toxicology model for developmental neurotoxicity testing. Congenit Anom (Kyoto) 55:1-16. https://doi.org/10.1111/cga.12079
OECD (2019) OECD guidelines for the testing of chemicals. Test No. 203: fish, acute toxicity test. Organisation of Economic Development

OECD (1992) OECD guidelines for the testing of chemicals. Section 2: effects on biotic systems. OECD Test Guideline 203: Fish, Acute toxicity test. Paris

OECD (2013) OECD guidelines for the testing of chemicals. Test No. 236: fish embryo acute toxicity (FET) test. Organisation of Economic Development

Padilla S, Corum D, Padnos B, Hunter DL, Beam A, Houck KA, Sipes N, Kleinstreuer N, Knudsen T, Dix DJ, Reif DM (2012) Zebrafish developmental screening of the ToxCast ${ }^{\mathrm{TM}}$ Phase I chemical library. Reprod Toxicol 33:174-187. https://doi.org/10.1016/j.reprotox. 2011.10.018

Paparella M, Scholz S, Belanger S, Braunbeck T, Bicherel P, Connors K, Faßbender C, Halder M, Lillicrap A, Liska R, Schirmer K, Stoddart G, Thomas P, Walter-Rohde S (2021) Limitations and uncertainties of acute fish toxicity assessments can be reduced using alternative methods. ALTEX 38(1):20-32. https://doi.org/10.14573/altex. 2006051

Peterson JSK, Bain LJ (2004) Differential gene expression in anthraceneexposed mummichogs (Fundulus heteroclitus). Aquat Toxicol 66: 345-355. https://doi.org/10.1016/j.aquatox.2003.10.005

Pinho BR, Santos M, Fonseca-Silva A, Valentão P, Andrade PB, Oliveira JMA (2013) How mitochondrial dysfunction affects zebrafish development and cardiovascular function: an in vivo model for testing mitochondria-targeted drugs. Br J Pharmacol 169(5):1072-1090. https://doi.org/10.1111/bph.12186

Pinho B, Reis S, Guedes-Dias P et al (2016) Pharmacological modulation of HDAC1 and HDAC6 in vivo in a zebrafish model: therapeutic implications for Parkinson's disease. Pharmacol Res 103:328-339. https://doi.org/10.1016/j.phrs.2015.11.024

Popovska-Gorevski M, Dubocovich ML, Rajnarayanan RV (2017) Carbamate insecticides target human melatonin receptors. Chem Res Toxicol 30:574-582. https://doi.org/10.1021/acs.chemrestox. 6b00301

Powell H, Swarner O, Gluck L, Lampert P (1973) Hexachlorophene myelinopathy in premature infants. J Pediatr 82:976-981. https:// doi.org/10.1016/S0022-3476(73)80428-7

Puhl AC, Milton FA, Cvoro A, Sieglaff DH, Campos JCL, Bernardes A, Filgueira CS, Lindemann JL, Deng T, Neves FAR, Polikarpov I, Webb P (2015) Mechanisms of peroxisome proliferator activated receptor $\gamma$ regulation by non-steroidal anti-inflammatory drugs. Nucl Recept Signal 13:nrs.13004. https://doi.org/10.1621/nrs.13004

Ramlan NF, Sata NSAM, Hassan SN, Bakar NA, Ahmad S, Zulkifli SZ, Abdullah CAC, Ibrahim WNW (2017) Time dependent effect of chronic embryonic exposure to ethanol on zebrafish: morphology, biochemical and anxiety alterations. Behav Brain Res 332:40-49. https://doi.org/10.1016/j.bbr.2017.05.048

Roche H, Bogé G, Pérès G (1994) Acute and chronic toxicities of colchicine in Brachydanio rerio. Bull Environ Contam Toxicol 52:69-73. https://doi.org/10.1007/BF00197359

Rovida C (2015) Toxicity testing in the 21 st century beyond environmental chemicals. ALTEX Altern zu Tierexperimenten 32:171-181. https://doi.org/10.14573/altex.1506201

Rovida C (2009) Re-evaluation of animal numbers and costs for in vivo tests to accomplish REACH legislation requirements for chemicals a report by the Transatlantic Think Tank for Toxicology (t4). ALTEX Altern zu Tierexperimenten 26:187-208. https://doi.org/ 10.14573/altex.2009.3.187

Russom CL, LaLone CA, Villeneuve DL, Ankley GT (2014) Development of an adverse outcome pathway for acetylcholinesterase inhibition leading to acute mortality. Environ Toxicol Chem 33: 2157-2169. https://doi.org/10.1002/etc.2662

Sancho E, Villarroel MJ, Fernández C, Andreu E, Ferrando MD (2010) Short-term exposure to sublethal tebuconazole induces 
physiological impairment in male zebrafish (Danio rerio). Ecotoxicol Environ Saf 73:370-376. https://doi.org/10.1016/j. ecoenv.2009.09.020

Schmitt EA, Dowling JE (1999) Early retinal development in the Zebrafish, Danio rerio: light and electron microscopic analyses. J Comp Neurol 404:515-536. https://doi.org/10.1002/(SICI)10969861(19990222)404:4<515::AID-CNE8>3.0.CO;2-A

Schock EN, Ford WC, Midgley KJ, Fader JG, Giavasis MN, McWhorter ML (2012) The effects of carbaryl on the development of zebrafish (Danio rerio) embryos. Zebrafish 9:169-178. https://doi.org/10. 1089/zeb.2012.0747

Scholz S, Sela E, Blaha L, Braunbeck T, Galay-Burgos M, García-Franco M, Guinea J, Klüver N, Schirmer K, Tanneberger K, Tobor-Kapłon M, Witters H, Belanger S, Benfenati E, Creton S, Cronin MTD, Eggen RIL, Embry M, Ekman D et al (2013) A European perspective on alternatives to animal testing for environmental hazard identification and risk assessment. Regul Toxicol Pharmacol 67:506530. https://doi.org/10.1016/j.yrtph.2013.10.003

Selderslaghs IWT, Blust R, Witters HE (2012) Feasibility study of the zebrafish assay as an alternative method to screen for developmental toxicity and embryotoxicity using a training set of 27 compounds. Reprod Toxicol 33:142-154. https://doi.org/10.1016/j.reprotox. 2011.08.003

Selderslaghs IWT, Hooyberghs J, Blust R, Witters HE (2013) Assessment of the developmental neurotoxicity of compounds by measuring locomotor activity in zebrafish embryos and larvae. Neurotoxicol Teratol 37:44-56. https://doi.org/10.1016/j.ntt.2013. 01.003

Selderslaghs IWT, Hooyberghs J, De Coen W, Witters HE (2010) Locomotor activity in zebrafish embryos: a new method to assess developmental neurotoxicity. Neurotoxicol Teratol 32:460-471. https://doi.org/10.1016/j.ntt.2010.03.002

Selderslaghs IWT, Van Rompay AR, De Coen W, Witters HE (2009) Development of a screening assay to identify teratogenic and embryotoxic chemicals using the zebrafish embryo. Reprod Toxicol 28:308-320. https://doi.org/10.1016/j.reprotox.2009.05. 004

Singh M, Khan H, Verma Y, Rana SVS (2019) Distinctive fingerprints of genotoxicity induced by $\mathrm{As}, \mathrm{Cr}, \mathrm{Cd}$, and $\mathrm{Ni}$ in a freshwater fish. Environ Sci Pollut Res 26:19445-19452. https://doi.org/10.1007/ s11356-019-05274-Z

Sipes NS, Martin MT, Reif DM, Kleinstreuer NC, Judson RS, Singh AV, Chandler KJ, Dix DJ, Kavlock RJ, Knudsen TB (2011) Predictive models of prenatal developmental toxicity from ToxCast highthroughput screening data. Toxicol Sci 123:1-54. https://doi.org/ 10.1093/toxsci/kfr220

Slaninova A, Smutna M, Modra H, Svobodova Z (2009) A review: oxidative stress in fish induced by pesticides. Neuro Endocrinol Lett 30(Suppl 1):2-12

Strähle U, Scholz S, Geisler R, Greiner P, Hollert H, Rastegar S, Schumacher A, Selderslaghs I, Weiss C, Witters H, Braunbeck T (2012) Zebrafish embryos as an alternative to animal experiments-a commentary on the definition of the onset of protected life stages in animal welfare regulations. Reprod Toxicol 33:128-132. https://doi. org/10.1016/j.reprotox.2011.06.121

Sukardi H, Chng HT, Chan ECY, Gong Z, Lam SH (2011) Zebrafish for drug toxicity screening: bridging the in vitro cell-based models and in vivo mammalian models. Expert Opin Drug Metab Toxicol 7: 579-589. https://doi.org/10.1517/17425255.2011.562197

Tassano E, Mirabelli-Badenier M, Veneselli E, Puliti A, Lerone M, Vaccari CM, Morana G, Porta S, Gimelli G, Cuoco C (2015) Clinical and molecular characterization of a patient with interstitial 6q21q22.1 deletion. Mol Cytogenet 8:31-37. https://doi.org/10. 1186/s13039-015-0134-7

Tilton FA, Bammler TK, Gallagher EP (2011) Swimming impairment and acetylcholinesterase inhibition in zebrafish exposed to copper or chlorpyrifos separately, or as mixtures. Comp Biochem Physiol Part C Toxicol Pharmacol 153:9-16. https://doi.org/10.1016/j.cbpc. 2010.07.008

Ton C, Lin Y, Willett C (2006) Zebrafish as a model for developmental neurotoxicity testing. Birth Defects Res Part A Clin Mol Teratol 76: 553-567. https://doi.org/10.1002/bdra.20281

Tyl R, Friedman M (2003) Effects of acrylamide on rodent reproductive performance. Reprod Toxicol 17(1):1-13. https://doi.org/10.1016/ S0890-6238(02)00078-3

Velki M, Di Paolo C, Nelles J et al (2017) Diuron and diazinon alter the behavior of zebrafish embryos and larvae in the absence of acute toxicity. Chemosphere 180:65-76. https://doi.org/10.1016/j. chemosphere.2017.04.017

Villavicencio-Lorini P, Klopocki E, Trimborn M, Koll R, Mundlos S, Horn D (2013) Phenotypic variant of brachydactyly-mental retardation syndrome in a family with an inherited interstitial $2 \mathrm{q} 37.3$ microdeletion including HDAC4. Eur J Hum Genet 21:743-748. https://doi.org/10.1038/ejhg.2012.240

Vliet SM, Ho TC, Volz DC (2017) Behavioral screening of the LOPAC1280 library in zebrafish embryos. Toxicol Appl Pharmacol 329:241-248. https://doi.org/10.1016/j.taap.2017.06. 011

Volz DC, Hipszer RA, Leet JK, Raftery TD (2015) Leveraging embryonic zebrafish to prioritize ToxCast testing. Environ Sci Technol Lett 2:171-176. https://doi.org/10.1021/acs.estlett.5b00123

von Hellfeld R, Brotzmann K, Baumann L, Strecker R, Braunbeck T (2020) Adverse effects in the fish embryo acute toxicity (FET) test: a catalogue of unspecific morphological changes versus more specific effects in zebrafish (Danio rerio) embryos. Environ Sci Eur 32: 122. https://doi.org/10.1186/s12302-020-00398-3

Wang Y, Yang G, Dai D, Xu Z, Cai L, Wang Q, Yu Z (2017) Individual and mixture effects of five agricultural pesticides on zebrafish (Danio rerio) larvae. Environ Sci Pollut Res 24(5):4528-4536. https://doi.org/10.1007/s11356-016-8205-9

Weston A, Caminada D, Galicia H, Fent K (2009) Effects of lipidlowering pharmaceuticals bezafibrate and clofibric acid on lipid metabolism in fathead minnow (Pimephales promelas). Environ Toxicol Chem 28:2648-2655. https://doi.org/10.1897/09-087.1

Williams SR, Aldred MA, Der Kaloustian VM et al (2010) Haploinsufficiency of HDAC4 causes brachydactyly mental retardation syndrome, with brachydactyly type E, developmental felays, and behavioral problems. Am J Hum Genet 87:219-228. https://doi. org/10.1016/j.ajhg.2010.07.011

Wolf JC, Wheeler JR (2018) A critical review of histopathological findings associated with endocrine and non-endocrine hepatic toxicity in fish models. Aquat Toxicol 197:60-78. https://doi.org/10.1016/j. aquatox.2018.01.013

Xia L, Zheng L, Zhou JL (2017) Effects of ibuprofen, diclofenac and paracetamol on hatch and motor behavior in developing zebrafish (Danio rerio). Chemosphere 182:416-425. https://doi.org/10.1016/ j.chemosphere.2017.05.054

Yang JD, Liu SH, Liao MH et al (2018) Effects of tebuconazole on cytochrome $\mathrm{P} 450$ enzymes, oxidative stress, and endocrine disruption in male rats. Environ Toxicol 33:899-907. https://doi.org/10. 1002/tox. 22575

Yang L, Ho NY, Alshut R, Legradi J, Weiss C, Reischl M, Mikut R, Liebel U, Müller F, Strähle U (2009) Zebrafish embryos as models for embryotoxic and teratological effects of chemicals. Reprod Toxicol 28:245-253. https://doi.org/10.1016/j.reprotox.2009.04. 013

Yang J-D, Liu S-H, Liao M-H, Chen R-M, Liu P-Y, Ueng T-H (2018) Effects of tebuconazole on cytochrome P450 enzymes oxidative stress and endocrine disruption in male rats. Environ Toxicol 33(8):899-907. https://doi.org/10.1002/tox.22575

Yen J, Donerly S, Levin ED, Linney EA (2011) Differential acetylcholinesterase inhibition of chlorpyrifos, diazinon and parathion in 
larval zebrafish. Neurotoxicol Teratol 33:735-741. https://doi.org/ 10.1016/j.ntt.2011.10.004

Yueh M-F, Tukey RH (2016) Triclosan: a widespread environmental toxicant with many biological effects. Annu Rev Pharmacol Toxicol 56:251-272. https://doi.org/10.1146/annurev-pharmtox010715-103417

Zhang C, Cheng F, Sun L, Zhuang S, Li W, Liu G, Lee PW, Tang Y (2015) In silico prediction of chemical toxicity on avian species using chemical category approaches. Chemosphere 122:280-287. https://doi.org/10.1016/j.chemosphere.2014.12.001

Zhang K, Yuan G, Werdich AA, Zhao Y (2020) Ibuprofen and diclofenac impair the cardiovascular development of zebrafish (Danio rerio) at low concentrations. Environ Pollut 258:113613. https://doi.org/10. 1016/j.envpol.2019.113613

Zhang T, Rawsom DM (1996) Feasibility studies on vitrification of intact zebrafish (Brachydanio rerio) embryos. Cryobiology 33:1-13. https://doi.org/10.1006/cryo.1996.0001

Zheng Y, Zhu X, Zhou P, Lan X, Xu H, Li M, Gao Z (2012) Hexachlorophene is a potent KCNQ1/KCNE1 potassium channel activator which rescues LQTs mutants. PLoS One 7:1-9. https:// doi.org/10.1371/journal.pone.0051820

Zindler F, Beedgen F, Brandt D, Steiner M, Stengel D, Baumann L, Braunbeck T (2019a) Analysis of tail coiling activity of zebrafish (Danio rerio) embryos allows for the differentiation of neurotoxicants with different modes of action. Ecotoxicol Environ Saf 186:109754. https://doi.org/10.1016/j.ecoenv.2019.109754

Zindler F, Beedgen F, Braunbeck T (2019b) Time-course of coiling activity in zebrafish (Danio rerio) embryos exposed to ethanol as an endpoint for developmental neurotoxicity (DNT) - Hidden potential and underestimated challenges. Chemosphere 235:12-20. https:// doi.org/10.1016/j.chemosphere.2019.06.154

Zindler F, Stoll S, Baumann L, Knoll S, Huhn C, Braunbeck T (2020a) Do environmentally relevant concentrations of fluoxetine and citalopram impair stress-related behavior in zebrafish (Danio rerio) embryos? Chemosphere 261:127753. https://doi.org/10.1016/j. chemosphere.2020.127753

Zindler F, Tisler S, Loerracher A-K, Zwiener C, Braunbeck T (2020b) Norfluoxetine is the only metabolite of fluoxetine in zebrafish (Danio rerio) embryos that accumulates at environmentally relevant exposure scenarios. Environ Sci Technol 54:4200-4209. https://doi. org/10.1021/acs.est.9b07618

Zhou SF, Zhou ZW, Yang LP, Cai JP (2009) Substrates inducers inhibitors and structure-activity relationships of human cytochrome $\mathrm{P} 450$ 2C9 and implications in drug development. Curr Med Chem 16(27): 3480-3675. https://doi.org/10.2174/092986709789057635

Publisher's note Springer Nature remains neutral with regard to jurisdictional claims in published maps and institutional affiliations. 